\title{
The Development of the Thalamic Motor Learning Area Is Regulated by Fgf8 Expression
}

\author{
Almudena Martinez-Ferre and Salvador Martinez \\ Instituto de Neurociencias, Universidad Miguel Hernández-Consejo Superior de Investigaciones Cientificas, 03550 San Juan de Alicante, Spain
}

Habenular nuclei play a key role in the control of motor and cognitive behavior, processing emotion, motivation, and reward values in the brain. Thus, analysis of the molecular and cellular mechanisms underlying the development and evolution of this region will contribute to a better understanding of brain function. The $F g f 8$ gene is expressed in the dorsal midline of the diencephalon, close to the area in which the habenular region will develop. Given that Fgf8 is an important morphogenetic signal, we decided to investigate the role of Fgf8 signaling in diencephalic development. To this end, we analyzed the effects of altered Fgf8 expression in the mouse embryo, using molecular and cellular markers. Decreasing Fgf8 activity in the diencephalon was found to be associated with dosage-dependent alterations in the epithalamus: the habenular region and pineal gland are reduced or lacking in Fgf8 hypomorphic mice. Actually, our findings indicate that $F \& 8$ may be the master gene for these diencephalic domains, acting as an inductive and morphogenetic regulator. Therefore, the emergence of the habenular region in vertebrates could be understood in terms of a phylogenetic territorial addition caused by de novo expression of $\mathrm{Fg} f \mathrm{i}$ in the diencephalic alar plate. This region specializes to permit the development of adaptive control of the motor function in the vertebrate brain.

\section{Introduction}

The habenular nuclei $(\mathrm{Hb})$ and pineal gland $(\mathrm{pg})$ constitute the epithalamus (ETh) in the dorsal diencephalon and are involved in pain processing, sleep-wake cycles, stress responses, and learning (Andres et al., 1999). Hb neurons suppress or facilitate motor and cognitive actions by means of dopaminergic-mediated mechanisms in the striatum, thus representing a new perspective to understand subcortical mechanisms of cognitive and emotive behaviors (Matsumoto and Hikosaka, 2007; Hikosaka et al., 2008). As a consequence, an analysis of $\mathrm{Hb}$ ontogenesis could contribute to our understanding of the molecular mechanisms in development and evolution that led to improve experience-related motor adaptation in vertebrate brains.

After neurulation, the diencephalon expresses $F g f 8$, a gene that is necessary for normal development of the forebrain (Garel et al., 2003; Storm et al., 2006) and midbrain/hindbrain region (Crossley and Martin, 1995; Martinez et al., 1999; Chi et al., 2003). Recently, several studies have examined the role of Fgf8 in the activity of two secondary organizers (Echevarría et al., 2003): the anterior neural ridge and the isthmic organizer (Chi et al., 2003; Alexandre et al., 2006; Nakamura et al., 2008). These re-

Received June 5, 2009; revised Sept. 10, 2009; accepted Sept. 15, 2009

This work was supported by Spanish Grants BFU2008-00588, Spanish Ministry of Science and Technology (MCT) Consolider Grant CSD2007-00023, and Integrated Project from European Union Grant LSHG-CT-2004-512003. A.M.-F. has a Formacion Personal Universitario grant from MCT. We thank C. Bueno for providing us HEK Fgf8expressing cells and M. Ródenas, C. Redondo, A. Torregrosa, and 0. Bahamonde for technical assistance. We also express our thanks to the agency BioEntelechia for having improved the English of this paper.

Correspondence should be addressed to Salvador Martinez, Experimental Embryology Laboratory, Instituto de Neurociencias, Universidad Miguel Hernández-Consejo Superior de Investigaciones Cientificas, Campus de San Juan,03550 San Juan de Alicante, Spain. E-mail: smartinez@umh.es.

DOI:10.1523/JNEUROSCI.2625-09.2009

Copyright $\odot 2009$ Society for Neuroscience $\quad$ 0270-6474/09/2913389-12\$15.00/0 gions are known to generate positional information controlling the histogenesis of neighboring domains.

The diencephalon is a complex region subdivided into three prosomeres, whose alar territories are as follows: P1 (pretectum), P2 (thalamus, $\mathrm{Hb}, \mathrm{pg}$, and choroid plexus), and P3 (prethalamus) (Puelles and Rubenstein, 2003). The zona limitans intrathalamica (ZLI) is a central boundary between the prethalamus and the thalamus that expresses sonic hedgehog (Shh), regulating both ventrodorsal and anteroposterior regionalization of the diencephalic neuroepithelium (Larsen et al., 2001; Kiecker and Lumsden, 2004; Vieira et al., 2005; Zeltser, 2005; Scholpp et al., 2006; Vieira and Martinez, 2006; Szabó et al., 2009; Vue et al., 2009). In addition to Shh, other morphogenetic signals provided by the roof plate mediate patterning activity in the diencephalon, including Wnts (Yamaguchi, 2001; Braun et al., 2003; Zhou et al., 2004; Lavado et al., 2008) and Bmps (Furuta et al., 1997; Lim et al., 2005).

A plethora of works have examined diencephalic regionalization and the role of Shh, Wnt, and Bmp signals (Lim and Golden, 2007). However, the function of Fgf8 in the diencephalon has not been sufficiently analyzed in detail. Indeed, a recent paper suggested a relevant role for Fgf8, since its ectopic expression produced alterations in the molecular and structural patterns of the mouse embryo and postnatal diencephalon (Kataoka and Shimogori, 2008). Thus, our aim here was to elucidate the molecular mechanisms underlying the suspected physiological activity of Fgf8 in diencephalic patterning and development. To this end, we analyzed two $F g f 8$ hypomorphic mouse lines with reduced levels of Fgf8 ( $F g f 8^{\text {neo/neo }}$ and Fgf $8^{\text {null } / \text { neo }}$ ) (Meyers et al., 1998). We show that normal expression of $F g f 8$ is necessary for the development of the $\mathrm{Hb}$ and pg in a dose-dependent manner. Furthermore, we show that Fgf8 signal promotes cell prolifera- 
E10.5

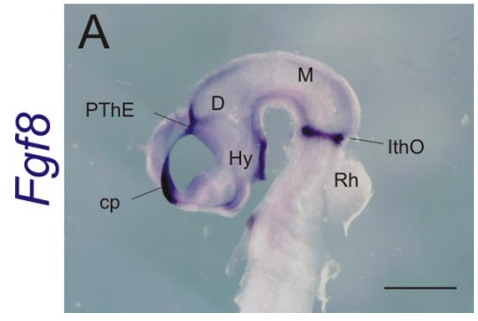

E11.5

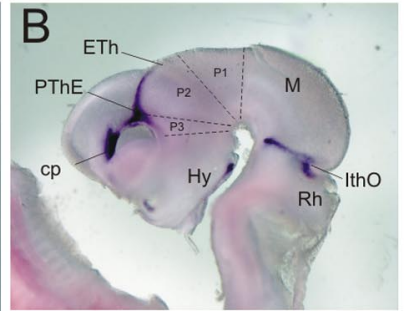

$\mathrm{E} 12.5$

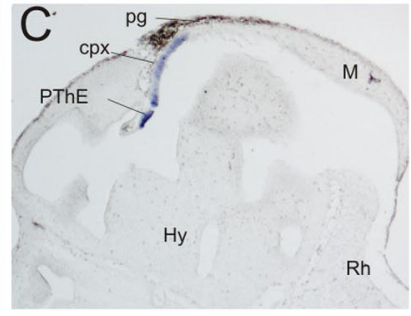

E14.5

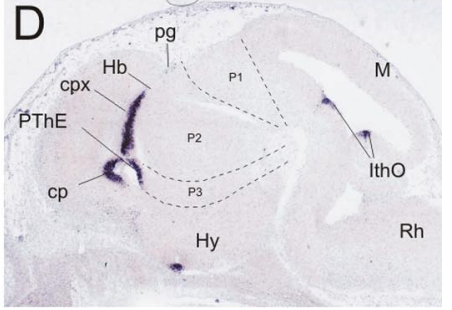

Figure 1. Dynamic expression of Fgf8 in the developing diencephalon. $A, B$, Whole-mount in situ hybridization of $F g f 8$ in dissected brains at E10.5 and E11.5, respectively. $A$, Strong expression of Fgf8 is observed in the cortical plate, isthmic organizer, hypothalamus, and dorsal diencephalon. $\boldsymbol{B}$, In the diencephalon, Fgf8 expression is present from dorsal P3 to dorsal P2.C, D, Sagittal sections of brains at E12.5 and E14.5, respectively. Fgf8 expression in the dorsal diencephalon covers the dorsalmost region of the alar P3 and P2 (from the prethalamic eminence to the epithalamus). Abbreviations: cp, Commissural plate; cpx, choroid plexus; D, diencephalon; ETh, epithalamus; Hy, hypothalamus; Ith0, isthmic organizer; M, mesencephalon; P1, prosomere 1; P2, prosomere 2; P3, prosomere 3; pg, pineal gland; PThE, prethalamic eminence; Rh, rhombencephalon. Scale bar: (in $\boldsymbol{A}) \boldsymbol{A}, \boldsymbol{C}, \boldsymbol{D}, 1 \mathrm{~mm} ; \boldsymbol{B}, \sim 800 \mu \mathrm{m}$.

tion and specifies regional characteristics in the dorsal diencephalon to generate a new dorsal domain that will develop as the epithalamus. The development of the $\mathrm{Hb}$ and the pg in vertebrates is regulated by the expression of an adequate dosage of $F g f$.

\section{Materials and Methods}

Mouse lines and genotyping. All animal experiments were performed in compliance with the Spanish and European Union laws on animal care in experimentation (Council Directive 86/609/EEC) and have been analyzed and approved by the Animal Experimentation Committee of our university. All Fgf8 and Wnt1 mutant mice were maintained on a C57BL/6 genetic background and generated as previously described (Chi et al., 2003). Green fluorescent protein (GFP) mutant mice were bred in our animal facilities. These mice ubiquitously express the GFP protein under the control of the $\beta$-actin promoter (Okabe et al., 1997). Fgf $8^{\text {neo/+ }}$ and Fgf $8^{\text {null } /+}$ mice were bred appropriately to produce $F g f 8^{\text {neo/neo }}$ and Fgf $8^{\text {null/neo }}$ mice. Wnt $1^{+/-}$mice were bred to obtain null mutant homozygotes. PCR genotyping was performed as previously described (McMahon et al., 1992; Meyers et al., 1998). To stage the embryos, the morning the vaginal plug was detected was considered as embryonic day 0.5 (E0.5). Heterozygous $F g f 8^{\text {neo/+ }}, F g f 8^{\text {null/+}}$, and $W n t 1^{+/-}$embryos did not present any abnormal phenotype and were used together with $\mathrm{Fg} 8^{+/+}$and $\mathrm{Wnt1}^{+/+}$embryos as controls.

In situ hybridization. Embryos were collected at various stages of gestation and were fixed overnight in $4 \%$ paraformaldehyde in PBS at $4^{\circ} \mathrm{C}$. After fixation, embryos were rinsed in PBT (PBS with $0.1 \%$ Tween 20 ), dehydrated in an ascending ethanol series, and stored in $100 \%$ ethanol at $-20^{\circ} \mathrm{C}$ before processing. Whole-mount in situ hybridization was performed as described previously (Shimamura et al., 1994). Digoxigenin and fluorescein-labeled RNA probes were prepared from plasmids kindly provided by the following: G. R. Martin, University of California, San Francisco, San Francisco, CA ( Fgf8), J. Guimera, Institute of Developmental Genetics, München, Germany (Wnt1), S. Lindsay, University of Newcastle, Newcastle, UK (Wnt $8 b)$, J. A. Belo, Universidade do Algarve, Faro, Portugal (Mkp3), J. L. R. Rubenstein, University of California, San Francisco, San Francisco, CA (Bmp4, $D l x 2)$, M. Frohmann, Stony Brook University, Stony Brook, NY (Gbx2), A. Lumsden, King's College London, London, UK (Irx3), and A. McMahon, Harvard University, Cambridge, MA (Shh). RNA-labeled probes were detected by alkaline phosphatase-coupled anti-digoxigenin and antifluorescein antibodies (Roche Diagnostics), and NBT/BCIP (nitroblue tetrazolium/5-bromo-4-chloro-3-indolyl phosphate) was used as a chromogenic substrate to detect the digoxigenin-labeled probes (Roche Diagnostics), whereas INT/BCIP (iodonitrotetrazolium/5-bromo-4-chloro-3indolyl phosphate) was used for the detection of the fluorescein-labeled probes (Roche Diagnostics). After hybridization, embryos were washed in PBT and stored at $4^{\circ} \mathrm{C}$ in PBT with $0.1 \%$ sodium azide.

Histological analysis and immunohistochemistry. For immunohistochemistry, embryonic brains were either embedded in paraffin wax (Polysciences) and sectioned at 8-12 $\mu \mathrm{m}$, or cryoprotected, embedded in Tissue-Tek (Richard-Allan Scientific), and sectioned at $20 \mu \mathrm{m}$ by means of a cryostat. Immunostaining with rabbit anti-phosphohistone-3 (PH3) (1:500; Millipore) was performed as described by Gimeno and Martinez (2007). Immunostaining with anti-Brn3a (also known as Pou4f1) (1:20; Santa Cruz Biotechnology) was performed as described previously (Puelles et al., 2003). Cresyl-violet staining and anti-calbindin (CB) (1:1000; Swant), anti-calretinin (CR) (1:1000; Swant), and anti-caspase3 staining (1:500; BD Biosciences Pharmingen) were performed on cryostat sections, following the manufacturer's recommendations. The presence of antibodies to $\mathrm{PH} 3, \mathrm{CB}$, and $\mathrm{CR}$ was detected using biotinylated anti-rabbit IgG and peroxidaseconjugated streptavidin (1:500; ABC Elite kit; Vector Laboratories). The staining reaction was performed using 3,3' -diaminobenzidine and hydrogen peroxide. Sections were mounted in Eukitt. Caspase-3 immunoreactivity was detected using biotinylated anti-rabbit IgG and Texas Red-conjugated streptavidin (1:1000; Vector Laboratories). Sections were mounted in glycerol and analyzed using a dissection microscope.

Cell proliferation and apoptosis analysis. E11.5 and E13.5 embryos were sectioned in the coronal plane. Sections were stained using either PH3 or caspase- 3 immunohistochemistry. The number of $\mathrm{PH}^{+}{ }^{+}$nuclei and caspase $-3^{+}$cells in the neuroepithelium was calculated for the dorsal part of the alar plate of the P2 diencephalon. Boxes were $\sim 10,500 \mu \mathrm{m}^{2}$ and were located from the epithalamus to the thalamus. These boxes are located in the most dorsal domain of the alar P2 in mutants.

Microsurgery. Fertilized chick (Gallus gallus) eggs were incubated at $37^{\circ} \mathrm{C}$ in a forced-air incubator and staged according to Hamburger and Hamilton (1995). HEK Fgf8-expressing cells (the plasmid was kindly provided by J. Guimera) or nontransfected cells were implanted into the right side of the prospective epithalamus of chick embryos at Hamburger and Hamilton stage 10 (HH10) (Garcia-Lopez et al., 2004). After surgery, the eggs were sealed and incubated until HH30 (7 d of incubation), and then fixed overnight in $4 \%$ paraformaldehyde. After fixation, the embryos were rinsed in PBT, dehydrated by successive incubations in ascending concentrations of ethanol, incubated in butanol $100 \%$ for $1 \mathrm{~h}$, and then embedded in paraffin wax before being sectioned and processed for immunohistochemistry.

Preparation of organotypic cultures: application of fluorescent tracer and isochronic transplants. Embryos were prepared for organotypic culture according to the technique described previously (Echevarría et al., 2001). However, mouse E9.5 neural tubes were dissected and were opened through the ventral midline, by opening the tube in a caudal-to-rostral direction, from the level of the otic vesicle to the optic vesicle. Implantation of Fgf8-soaked beads (R\&D Systems) or beads soaked in PBS was performed as previously described (Crossley et al., 1996; Vieira and Martinez, 2005). Heparin acrylic beads (Sigma-Aldrich) were used. For organotypic cultures of embryos at E13.5, the telencephalic vesicles were removed, neural tubes were dissected and were opened through the ventral midline. 1,1'-Dioctodecyl-3,3,3',3'-tetramethylindo-carbocyanine (DiI) crystals were placed in the ventricular epithalamic neuroepithelium. The epithalamus is clearly distinguishable at E13.5 as a small protrusion in which the retroflexus tract has its origin and in which the stria medullaris ends. Explants were cultured for $20 \mathrm{~h}$ and then photographed under a dissecting fluorescence microscope. Homotopic and isochronic 


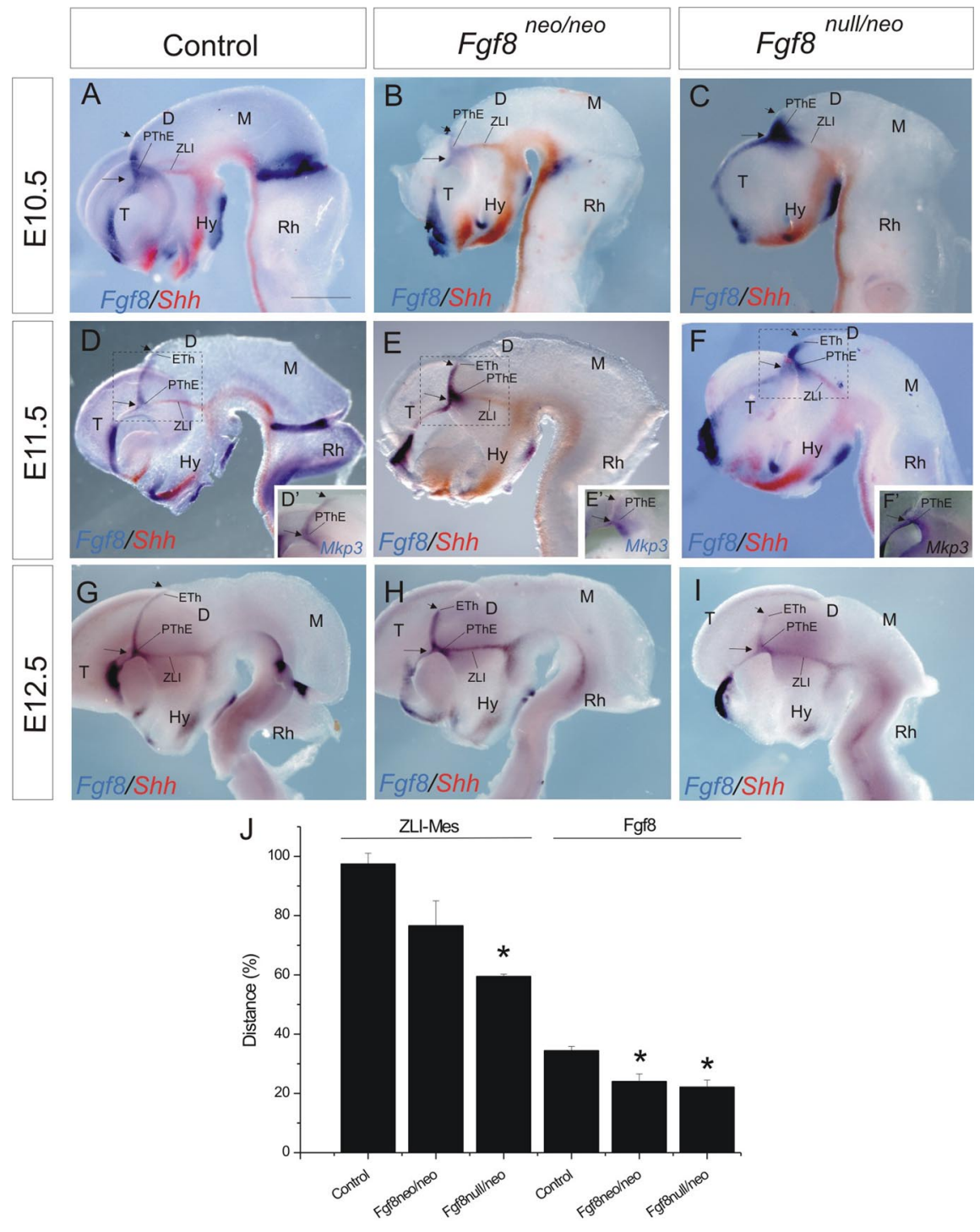

Figure 2. Lateral view of neural tube whole mounts in situ hybridized for $F g f 8$ (blue) and $S h$ (red). Each row presents the

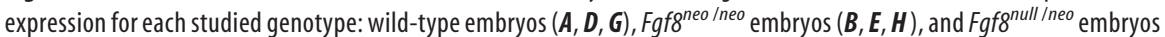
$(\boldsymbol{C}, \boldsymbol{F}, \boldsymbol{I})$. Three different embryonic stages have been studied for each genotype; embryos at $\mathrm{E} 10.5(\boldsymbol{A}-\boldsymbol{C})$, embryos at $\mathrm{E} 11.5(\boldsymbol{D}-\boldsymbol{F})$, and embryos at E12.5 $(\mathbf{G}-\mathbf{I}) . \mathbf{D}^{\prime}-\boldsymbol{F}^{\prime}$, Higher-power view of the insets in $\mathbf{D}-\boldsymbol{F}$, respectively, showing Mkp3 expression by in situ hybridization. $A-I$, The long arrows indicate the most dorsal region of the PThE and ZLI, whereas the short arrows indicate the caudal edge of $F g f 8$ expression. $\boldsymbol{D}^{\prime}-\boldsymbol{F}^{\prime}$, The long arrows indicate the PThE, whereas the short arrows indicate caudal limit of $M k p 3$ expression. In $\boldsymbol{D}, \boldsymbol{E}$, and $\mathbf{G}-\boldsymbol{I}$, the left telencephalic hemisphere was removed to enable visualization of the diencephalon. J, Histograms presenting as percentages the average $\pm S D$ of the distance between the dorsal tip of $Z L I$ and the caudal edge of Fgf8 expression (to measure Fgf8 expression domain) or the $D-M$ limit (to measure caudal diencephalic length). The asterisks indicate the values that were found to be statistically significant by $t$ test analysis [control $(n=7), 97.43 \pm 3.6 ; F_{\text {gff }}^{\text {neo } / \text { neo }}(n=7), 76.58 \pm 8.37(0.08)$; and Fgf8 $^{\text {null/neo }}(n=7), 59.48 \pm 0.74(0.04)$ for ZLI-M distance; control $(n=3), 34.4 \pm 1.42 ;$ Fgfr $^{\text {neo } / \text { neo }}(n=3), 24.05 \pm$ 2.55 (0.03); and Fgf8 $8^{\text {null } / \text { neo }}(n=3), 22.15 \pm 2.34(0.02)$ for the distance covered by Fgf8 expression]. Abbreviations: $D_{\text {, }}$ Diencephalon; ETh, epithalamus; Hy, hypothalamus; M, mesencephalon; PThE, prethalamic eminence; Rh, rhombencephalon; T, telencephalon; ZLI, zona limitans intrathalamica. Scale bar: (in $\boldsymbol{A}) \boldsymbol{A}-\boldsymbol{C}, 650 \mu \mathrm{m} ; \boldsymbol{D}-\boldsymbol{F}, 800 \mu \mathrm{m} ; \boldsymbol{G}-\mathbf{I}, 1 \mathrm{~mm}$.

grafts were performed by using GFP mice as donors. The epithalamus from donor organotypic cultures (obtained from GFP mice) was grafted into the epithalamus of E13.5 wild-type (WT) organotypic cultures, which were subsequently cultured for $36 \mathrm{~h}$.

\section{Results}

\section{Dynamic expression of Fgf8 in the diencephalon}

We performed in situ hybridization at different stages of embryonic development to follow the pattern of expression of $F g f 8$ in the developing mouse diencephalon. At early stages of develop- ment, from E8.5 to E9.5, Fgf8 appeared in the neural epithelium on the midbrain/ hindbrain region and in the dorsal midline of the anterior neural plate. As development progresses, at E10.5, anterior expression extended caudally toward the prethalamic eminence (PThE) in the anterior diencephalon (P3) (Fig. 1A). Afterward, this diencephalic domain of $F g f 8$ expression progressively expanded from the PThE to the ETh, in narrow bilateral longitudinal domains close to the roof plate, at the insertion of the choroid plexus (cpx) in the thalamic alar plates: the tenia thalami, reaching caudally the pineal stalk by stage E12.5 (Fig. $1 A-C$ ). Subsequently, at E14.5, when the diencephalon has developed into a more complex cellular structure, the expression of Fgf8 was maintained in this longitudinal domain of the tenia thalami from the PThE to the ETh (Fig. 1D). Analysis of later developmental stages revealed that Fgf 8 is no longer expressed in the developing diencephalic neuroepithelium (data not shown). This domain of Fgf8 expression in the mouse diencephalon is equivalent to that reported in the developing chick diencephalon (Crossley et al., 2001).

To define the anteroposterior location of Fgf8 expression in the dorsal diencephalon with greater precision, we performed whole-mount double in situ hybridization for Fgf8 and Shh; this allows visualization of the ZLI at the P3/P2 limit (Fig. $2 A, D, G)$. As early as E10.5, Fgf8 expression was not restricted to the PThE, but also covered a domain posterior to the ZLI, in the anterior ETh (Fig. $2 \mathrm{~A}$ ). As described above, this epithalamic domain progressively extended caudally to reach the pineal stalk in the roof plate at E12.5 (Fig. 2D, G).

We decided to look for possible alterations in the pattern of expression of $F g f 8$ and Shh in Fgf8 mouse hypomorphs. Whereas Shh expression in the ZLI was not modified in the hypomorphs, the dynamic pattern of Fgfs expression in the diencephalon was disrupted. This can be clearly seen in Figure $2 D-I$, which shows how, in both $F g f 8^{\text {neo/neo }}$ and Fgf $8^{\text {null } / \text { neo }}$ embryos, the diencephalic expression of Fgf8 was still present in the prethalamic tenia thalami, but the expressing domain in the epithalamic tenia was progressively reduced in its caudal extension. Thus, these mutants present an anterior shift of $F g f 8$ expression in the tenia thalami that was progressively more evident in more severe mutants. Additionally, the data reported by Meyers et al. (1998), together with our $M k p 3$ expression analysis in the diencephalon (Fig. 2; supplemental Fig. 2, available at www.jneurosci.org as supplemental material) demonstrates lower Fgf8 activity in the mutant diencephalon. 

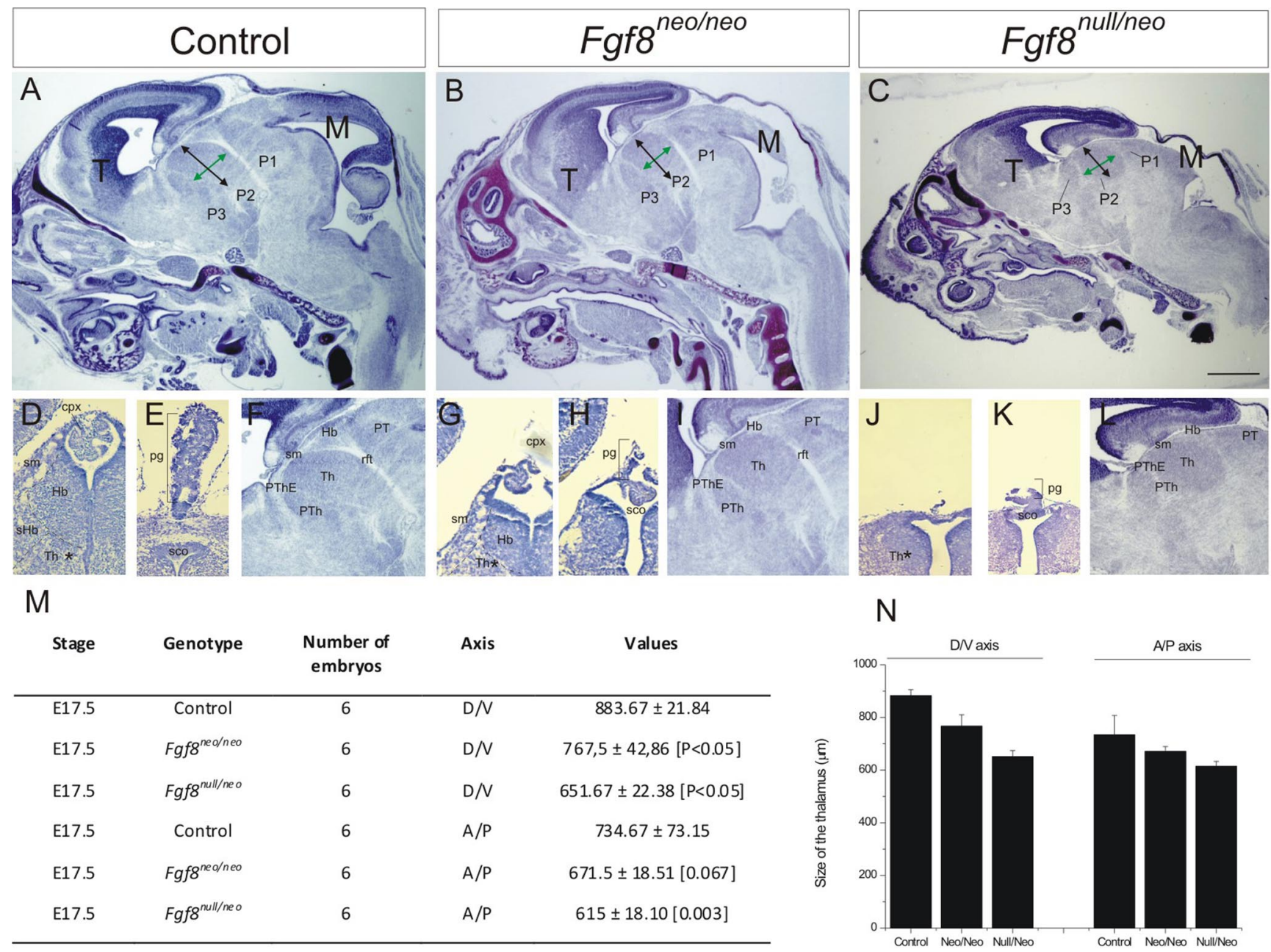

Figure 3. Comparative analysis of $20 \mu \mathrm{m}$ sagittal and coronal sections from E17.5 wild-type, Fgf8 ${ }^{\text {neo } / \text { neo }}$, and Fgf8 ${ }^{\text {null } / \text { neo }}$ embryos. Brains were stained with cresyl violet. To ensure accurate comparison of the same brain positions, brains were aligned by comparing those sections in which the retroflexus tract was detectable (sagittal sections) and aligning the ventricular relieves (coronal sections). The marked region in $\boldsymbol{A}-\boldsymbol{C}$ shows the size of the thalamus in the diencephalon. $A-C, F, I, L$, Analysis of lateral-sagittal sections. $\boldsymbol{D}, \boldsymbol{E}, \boldsymbol{G}, \boldsymbol{H}, \boldsymbol{J}, \boldsymbol{K}$, Analysis of coronal sections. $\boldsymbol{F}, \boldsymbol{I}, \boldsymbol{L}$, Several diencephalic structures in mutant embryos present a reduced size, such as the dorsal thalamus and prethalamic eminence. $\boldsymbol{D}, \boldsymbol{E}, \boldsymbol{G}, \boldsymbol{H}, \boldsymbol{J}, \boldsymbol{K}$, Several other structures seem to be strongly reduced or disappeared (choroid plexus, habenula, and pineal gland) in Fgf8 mutants. $M$, The table presents the average \pm SD of dorsoventral (black arrows) and anteroposterior (green arrows) dimensions of the thalamus. Results of $t$ test analyses are shown for each mutant compared with wild type. Values that are $<0.05$ were considered to be statistically significant. $N$, Histograms representing the average size $( \pm S D$ ) of the thalamus, measuring the distance from the ZLI to the retroflex tract (green arrows) and from the stria medullaris to the ventral part of alar P2 (black arrow). Abbreviations: $\mathrm{cpx}$, Choroid plexus; $\mathrm{Hb}$, habenula; $\mathrm{M}$, mesencephalon; $\mathrm{P1}$, prosomere 1; $\mathrm{P2}$, prosomere 2; P3, prosomere 3; pg, pineal gland; PT, pretectum; PTh, prethalamus; PThE, prethalamic eminence; rft, retroflexus tract; sco, subcommissural organ; sHb, subhabenula; sm, stria medullaris; T, telencephalon; Th, thalamus. Scale bar: (in C) A-C, $1.6 \mathrm{~mm} ; \boldsymbol{F}, \mathbf{I}, \boldsymbol{L}, 900 \mu \mathrm{m} ; \boldsymbol{D}, \boldsymbol{E}, \boldsymbol{G}, \boldsymbol{H}, \mathbf{J}, \boldsymbol{K}, \sim 200 \mu \mathrm{m}$.

We show quantitative data that support the anterior shift of Fgf8 expression in the ETh. We examined the size of the caudal diencephalon (from the ZLI to the limit between P1 and the mesencephalon) and the size of $F g f 8$ expression domain (from the ZLI to the caudal edge of this domain) in WT and mutant embryos (Fig. $2 J)$. We have detected a significant reduction of the Fgf8 expression domain in the ETh of the hypomorph embryos: while at E12.5 this domain covers in WT embryos the $34 \%$ of the caudal diencephalon, in the hypomorphs it covers only the $24-22 \%$. The reduction of diencephalic length is only significant in Fgf8 null/neo embryos (Fig. 2J).

Dorsal structures are diminished or absent in the diencephalon of Fgf8 mutants

The level of functional Fgf8 mRNA in Fgf $8^{\text {neo/neo }}$ and in Fgf $8^{\text {null/neo }}$ embryos has been estimated to be $\sim 40$ and $20 \%$, respectively, of that found in wild-type embryos (Meyers et al., 1998), the cause of the phenotype being thought to lie in the midbrain/hindbrain and anterior prosencephalic regions (Chi et al., 2003; Storm et al., 2006).

To determine the role of $F g f 8$ expression in the diencephalon, we first examined the possible anatomical effects of reducing Fgf8 expression during the development of the diencephalon. Brains of E17.5 embryos expressing different amounts of functional Fgf8 mRNA were processed and structurally analyzed. Analysis of sagittal and coronal sections of Fgf $8^{\text {neo /neo }}$ and Fgf $8^{\text {null /neo }}$ embryos clearly revealed that the severity of perturbation of diencephalic morphology is Fgf8 dosage sensitive (Fig. 3; supplemental Fig. 3, available at www.jneurosci.org as supplemental material). There is an obvious reduction in the size of the alar diencephalon in both its anteroposterior and dorsoventral extensions (Fig. 3A-C). More specifically, decreased expression of $F g f 8$ was accompanied by a significant reduction or even absence of the diencephalic structures in which it is normally expressed (PThE 

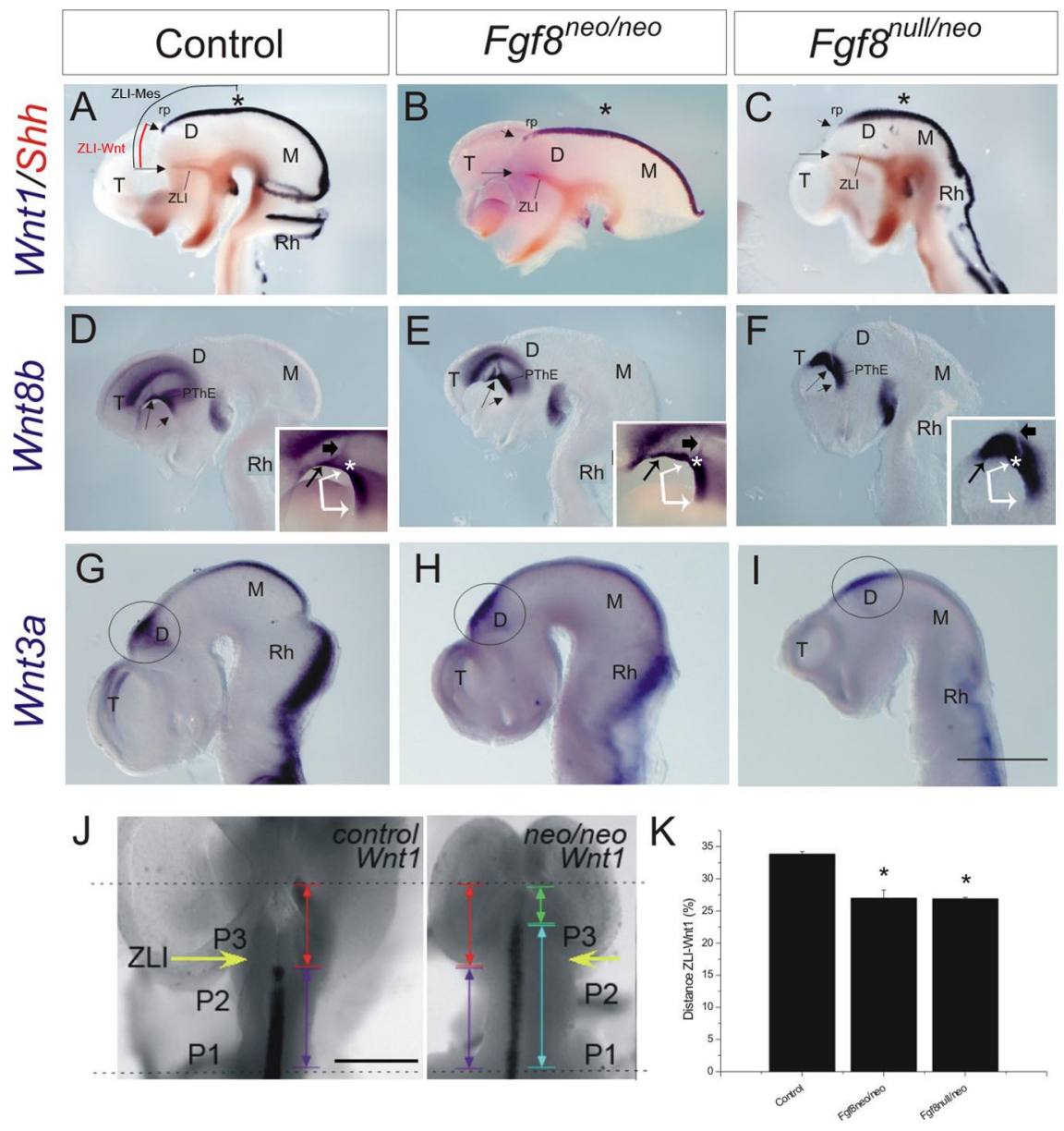

Figure 4. Analysis of Wnt genes expressions in control, Fgf8 ${ }^{\text {neo } / \text { neo }}$, and Fgf8 ${ }^{\text {null /neo }}$ embryos. A-I, In situ hybridization performed at E11.5 $(\boldsymbol{A}-\boldsymbol{F})$ and at E10.5 $(\mathbf{G}-\boldsymbol{I})$. $\boldsymbol{A}-\boldsymbol{C}$, The long arrows indicate the dorsal end of the ZLI, whereas the short arrows indicate the rostral edge of Wnt1 expression in the diencephalic neuroepithelium. The asterisks mark the D-M limit defined by morphological changes in the embryo. Note that the distance between the rostral limit of the Wnt 1 expression domain and the ZLI is reduced in mutant embryos. $\boldsymbol{D}-\boldsymbol{F}$, The long arrows indicate the caudalmost region of the PThE, whereas the short arrows indicate the most ventral part of the PThE. The insets show a higher magnification of the Wnt8b expressions in the PThE (between white arrows) and telencephalic roof plate (long black arrow) in control, Fgf8 ${ }^{\text {neo } / \text { neo }}$, and Fgff ${ }^{\text {null } / \text { neo }}$ mice. The large black arrows label the Wnt $8 b$-negative diencephalic roof plate, and the asterisks localize in the roof plate the diencephalic-telencephalic limit. Note that the expression of Wnt $8 b$ in the PThE of Fgf 8 mutant embryos is not affected (the white arrows and interarrow segments have the same size because they were copied and pasted in the three insets) and slightly affected in the telencephalic roof plate. The circles in $\mathbf{G}-\mathbf{I}$ indicate the region of the diencephalon in which weak expression of Wnt3a was detected in $\mathrm{Fgfr}^{\text {neo }} /{ }^{\text {neo }}$. Wnt3a

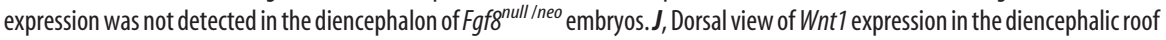
plate by in situ hybridization. The colored arrows indicate the size of Wnt1-expressing roof plate (purple in WT and blue in Fgf8 ${ }^{\text {neo } / \text { neo }}$ mutant), as well as the rostral Wnt7-negative roof plate area (red in WT and green in Fgf ${ }^{\text {neo } / \text { neo }}$ mutant). The yellow arrows label the central area of ZLI. $\boldsymbol{K}$, Histograms presenting as a percentage the average distance $( \pm S D)$ between the rostral end of Wnt1 expression and the position of the ZLI (see representative lines in $A$ ). The asterisks indicate the values found to be statistically significant by $t$ test analysis [control $(n=2), 33.83 \pm 0.38 ; F_{\text {gff }}^{\text {neo } / \text { neo }}(n=2), 27 \pm 0.17(0.01)$; and Fgf8 ${ }^{\text {null } / \text { neo }}$ $(n=2), 26.89 \pm 0.20(0.002)]$. Abbreviations: $D$, Diencephalon; $M$, mesencephalon; $P 1$, prosomere $1 ; P 2$, prosomere 2; $P 3$, prosomere 3; PThE, prethalamic eminence; Rh, rhombencephalon; $r p$, roof plate; $T$, telencephalon; ZLI, zona limitans intrathalamica. Scale bar: (in $\boldsymbol{I}) \boldsymbol{A}-\boldsymbol{F}, \mathbf{1} .4 \mathrm{~mm} ; \boldsymbol{G}-\boldsymbol{I}, 1.2 \mathrm{~mm}$; (in $\boldsymbol{J}) \boldsymbol{J}, \boldsymbol{K}, 0.8 \mathrm{~mm}$.

and ETh), which in turn also affected other neighboring thalamic structures.

Thus, both $F g f 8^{\text {neo/neo }}$ and $F g f 8^{\text {null/neo }}$ embryos presented a progressive reduction or absence (in the most severe hypomorphs) of the choroid plexus ( $\mathrm{P} 3$ and $\mathrm{P} 2$ roof plates) and pineal gland ( $\mathrm{P} 2$ roof plate) (Fig. 3D,E,G, $H, J, K)$. Moreover, the most dorsal region of the alar P2 (thalamus and epithalamus) as well as the dorsal part of the alar P3 region (PThE) were affected in $F g f 8^{\text {neo /neo }}$ embryos, with this phenotype being more severe in Fgf8 $8^{\text {null } / n e o}$ embryos (Fig. $3 F, I, L$ ). In the ETh, the habenular nuclei together with their main efferent projection tract, the ret- roflexus fascicle (rtf), were reduced or absent in $\mathrm{Fg} f 8^{\text {neo } / \text { neo }}$ and in $\mathrm{Fg} f 8^{\text {null } / \text { neo }} \mathrm{em}$ bryos, respectively. The thalamus, located ventral to the ETh, was reduced in size, mainly in its dorsoventral extension (Fig. $3 M, N)$. The PThE was visibly reduced in its dorsal extension to the roof plate (Fig. $3 F, I, L)$. Moreover, the stria medullaris $(\mathrm{sm})$, which is an axonal tract that originates in the posterior septal nuclei, lateral preoptic area, and anterior thalamic nuclei, courses longitudinally into the PThE and ends in the ETh (habenular region), crossing the midline in the habenular commissure (hc), was remarkably reduced in $F g f 8^{\text {neo/neo }}$ and disappeared in Fgf ${ }^{\text {null } / \text { neo }}$ mutant embryos (Fig. $\left.3 F, I, L\right)$. This description corresponded to the more frequent phenotypes observed in both hypomorph genotypes, but some degree of phenotypic variability has been observed in $<20 \%$ of embryos.

Concerning other areas of the P2 and P3 alar plate, we found a smaller thalamus (Th) in mutant mice as described above. However, no alterations were observed in the prethalamic derivatives (PTh).

Thus, a progressive decrease of Fgf8 signaling in Fgf $8^{\text {neo/neo }}$ and Fgf $8^{\text {null ineo }}$ mutants led to a progressive disappearance of the habenular region and pineal gland (the epithalamus), and, in parallel, to a size reduction of the thalamus. This phenotype may be attributable to alterations in cellular processes such as cell proliferation, cell death, and/or modifications in cellular migration. These alterations could be a consequence of Fgf8 activity reduction, either directly and/or indirectly through modification of the expression of other genes regulated by Fgf8.

\section{Wnt1, Wnt3a, and Bmp4 expression is altered in Fgf8 hypomorphic mice}

To better understand the molecular mechanisms underlying the observed structural phenotype, we carefully compared the expression patterns of other signaling genes that have been suggested to play a morphogenetic role in diencephalic development (Crossley et al., 2001; Lim and Golden, 2007). Our analysis was focused on E11.5 mouse embryos, since, at this stage, reduced $F g f 8$ expression is evident in the diencephalon, in the absence of an obvious morphological phenotype (Figs. 4-8).

Previous reports demonstrated that reductions in Fgf 8 gene dosage lead to the expansion of Wnt gene expression domains in the telencephalon at E9.5 (Storm et al., 2006). Thus, to explore whether this situation also occurs in the diencephalon, we compared the expression patterns of three Wnt genes expressed in the dorsal diencephalon: Wnt1, Wnt8b, and Wnt3a in WT and hypomorph mouse embryos. Wht1 expression in wild-type embryos was restricted to the roof plate, from the isthmus to the ETh (Fig. 
4A). In embryos in which Wnt1 expression was analyzed together with $\operatorname{Shh}$ (as a ZLI marker), we observed that the Wnt1 expression pattern was altered in the $\mathrm{Fg} f 8$ mutants (Fig. $4 B, C$ ). These embryos presented a progressively anterior expansion of the Wnt1 expression domain, in proportion to the reduction of Fgf8 expression, suggesting that Fgf8 may control the establishment of the rostral end of Wnt1 expression in the diencephalic roof plate. To verify this possibility, we measured the distance between the rostral end of Wnt 1 expression and the position of the ZLI (marked by Shh) (Fig. 4A-C) or the anterior limit of PThE (Fig. $4 J$ ). The distance between ZLI and anterior Wnt1 expression is clearly reduced in relation to the size of caudal diencephalon: from $34 \%$ in WT to $27-26 \%$ approximately in both hypomorph phenotypes (Fig. $4 K$ ).

$W n t 8 b$ is another member of the Wnt family that is expressed in diverse regions of the mouse brain. Specifically, Wnt8b is expressed in the dorsal telencephalon (Storm et al., 2006) and in the PThE of the diencephalic alar plate, as well as in the retromamillary region of the basal plate (Fig. 4D-F). Wnt8b expression in the PThE was either unaffected or only slightly affected compared with the lateral expansion seen in the telencephalic vesicle of Fgf $8^{\text {null } / \text { neo }}$ mutants (Fig. $4 E, F$ ).

Finally, a previous report using genetic fate mapping has demonstrated that the $W n t 3 a$ cell lineage contributes to diverse structures in the diencephalon, midbrain, and spinal cord (Louvi et al., 2007).

Wnt3a expression was mapped in the entire dorsal thalamic epithelium and mantle layer (Louvi et al., 2007). However, we found that $W n t 3 a$ expression was strongly reduced in $F g f 8^{\text {neo/neo }}$ and almost abolished in Fgf $8^{\text {null } / n e o}$ mutants, with only a narrow expression domain restricted to the dorsal midline epithelium remaining (Fig. 4G-I). This dose-dependent phenotype and the possible importance of the Wnt3a expression pattern in developing thalamic nuclei (Louvi et al., 2007) motivated us to carefully examine whether Wnt3a expression is Fgf8 dependent. Thus, we analyzed the expression of Wnt3a in mouse neuroepithelial culture explants, in which recombinant Fgf8-soaked beads were inserted to perform gain-of-function experiments. PBS-soaked beads were used as control. Fgf8 beads were inserted into the diencephalon of anterior neural tube explants from E9.5 embryos and cultured for $24 \mathrm{~h}$ (Fig. 5) (Echevarría et al., 2001, 2005). We observed that Fgf8 beads implanted in the diencephalon of E9.5 WT $(n=3)$ and mutant $(n=4)$ mice induced $W n t 3 a$ expression ( 3 of $3 \mathrm{WT} ; 4$ of $4 \mathrm{Fg} f 8^{\text {null /neo }}$ ) in the neuroepithelium of the dorsal thalamus, whereas no induction was detected by inserting PBS beads, either in WT ( $n=2$ of 2) or in Fgf8 ${ }^{\text {null } / \text { neo }}(n=2$ of 2$)$ explants (Fig. 5C).

Moreover Fgf8 beads were able to induce $M k p 3$ expression ( $n=2$ of 2 in WT and $n=2$ of 2 in Fgf $8^{\text {null } / n e o}$ mutants), which is downstream of Fgf8 signal (Fig. 5D), demonstrating that the experimentally generated Fgf8 signal was functional and that the
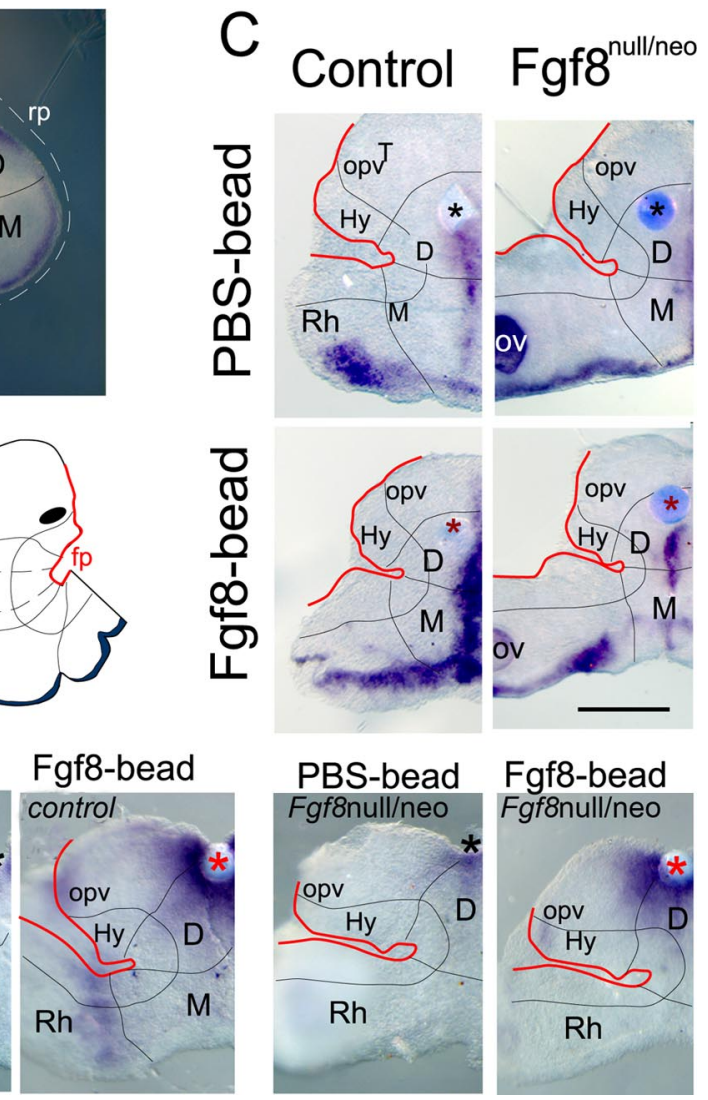

Figure 5. Experimental analysis of Wnt3a expression in the diencephalon. $\boldsymbol{A}$, Wnt3a expression in a wild-type embry0 at E9.5. $\boldsymbol{B}$, Schematic representation of the neural tube explant technique. Embryos were dissected and opened along the ventral midline floor plate; Hy, hypothalamus; M, mesencephalon; opv, optic vesicle; ov, otic vesicle; Rh, rhombencephalon; rp, roof plate; $T$, telencephalon. Scale bar: (in $\boldsymbol{C}) \boldsymbol{A}, 550 \mu \mathrm{m} ; \boldsymbol{C}, \boldsymbol{D}, 650 \mu \mathrm{m}$.

hypomorphic epithelium was sensible to it. PBS-soaked did not produce any inductive effect $(n=5$ of 5$)$.

Since the diencephalic dorsal midline was affected in Fgf $8^{\text {null } / \text { neo }}$ and $\mathrm{Fg} f 8^{\text {пео /nеo }}$ embryos, we examined the expression of Bmp4, which is implicated in the regulation of the specification and differentiation of the dorsal prosencephalon (Hébert et al., 2002; Storm et al., 2006). At E11.5, Bmp4 was expressed in the caudal region of the diencephalic roof plate, at the level of the pineal anlage, adjacent to the caudal pole of the $F g f 8$ expression domain (Fig. 6A-C), as has been reported in chick embryos (Crossley et al., 2001). Even though we detected Bmp4 expression in the dorsal midline of both mutant phenotypes (Fig. $6 H, I$ ), it appeared rostralized, closer to the telencephalic vesicles, and with a weaker expression than in WT embryos (Fig. 6D-I).

\section{Effects of reduced Fgf8 expression on Gbx2, Dlx2, and Otx2 expression patterns}

Afterward, we analyzed the expression of the $G b \times 2, D l \times 2$, and Otx2 transcription factors, both in Fgf $8^{\text {neo/neo }}$ and Fgf $8^{\text {null/neo }} \mathrm{mu}-$ tants at E11.5 (Fig. 7). In the wild-type embryo, Gbx2 expression was located in the thalamic mantle layer (Fig. $7 A$ ), whereas $D l x 2$ was present in the ventricular and mantle layers of the prethalamic region (Fig. 7D) (Bulfone et al., 1993; Rubenstein et al., 1994). Gbx2 expression was progressively reduced in extension and intensity in the thalamus of both Fgf8 hypomorphic pheno- 

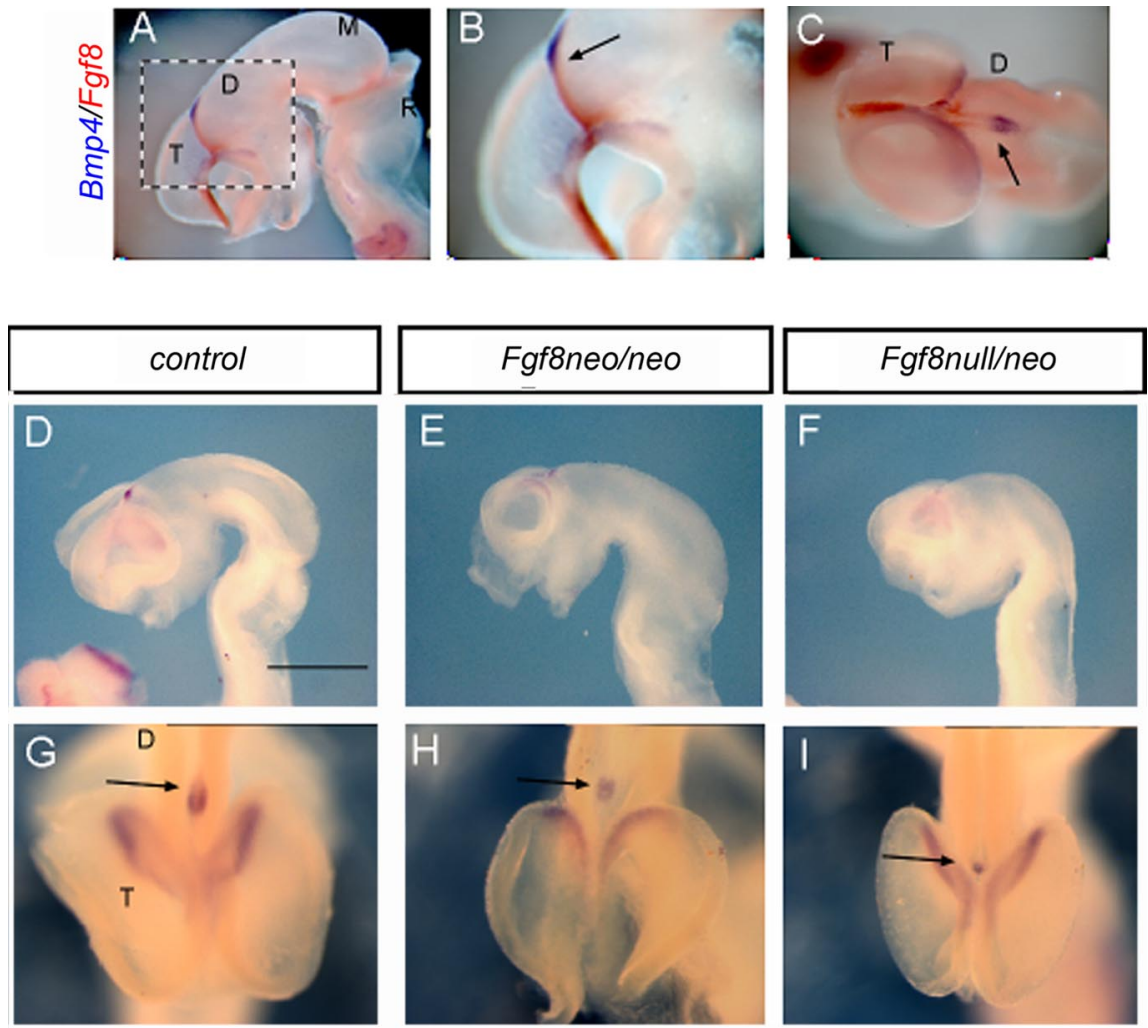

Figure 6. Analysis of $B m p 4$ and Fgf8 expression at E11.5. A-C, In situ hybridization for Bmp4 (blue) and Fgf8 (red). D-I, In situ hybridization for Bmp4.A, $\boldsymbol{B}, \boldsymbol{D}-\boldsymbol{F}$, Lateral view. $\boldsymbol{C}, \mathbf{G}-\mathbf{I}$, Dorsal view. The arrow in $\boldsymbol{B}$ indicates the diencephalic region in which the expression of Bmp 4 and $F g f 8$ contact. The arrows in $\mathbf{G}-\mathbf{I}$ indicate $B m p 4$ expression in the diencephalic roof plate. Abbreviations: $D$, Diencephalon; $\mathrm{M}$, mesencephalon; $\mathrm{T}$, telencephalon; $\mathrm{Rh}$, rhombencephalon. Scale bar: (in $\boldsymbol{D}) \boldsymbol{A}, 970 \mu \mathrm{m} ; \boldsymbol{B}, 750 \mu \mathrm{m} ; \boldsymbol{C}, 900 \mu \mathrm{m}$; D-F, $1.4 \mathrm{~mm} ; \mathbf{G}-\mathbf{I}, 600 \mu \mathrm{m}$.

types (Fig. $7 A-C$ ). However, there were no differences in prethalamic $D l x 2$ expression (Fig. $7 D-F$ ). Moreover, no differences were found in Otx2 expression by in situ hybridization in the diencephalon of WT and mutant embryos (data not shown).

\section{Wnt1 activity does not modulate Fgf8, Gbx2, or Wnt3a expression in the diencephalon}

To further elucidate whether the rostralized expression of Wnt1 in the diencephalon of hypomorphic embryos could have any effect on $F g f 8$ expression and thus be responsible for the reduced expression of $W n t 3 a$ and $G b x 2$, we analyzed the expression of Fgf8, Gbx2, and Wnt3a in Wnt1 ${ }^{-1-}$ embryos (Fig. 8). In all analyzed $W n t 1^{-1-}$ embryos, the expression of Gbx2 (Fig. 8 A, B), Fgf8 (Fig. $8 C, D$ ), and Wnt3a (Fig. $8 E, F$ ) was found to be unaltered, suggesting that the disruption of Gbx2 and Wnt3a in the Fgf8 mutant mice is independent of Wnt1.

\section{Reduced cell proliferation in the epithalamus of hypomorphic mice}

So far, we had found a reduction or disappearance of the dorsalmost structures in P2 and P3, together with a downregulation of several genes expressed in the alar and roof plates of these prosomeres during diencephalic development. Previous studies have suggested that Fgf8 functions as a proliferation factor (Lee et al., 1997; Xu et al., 2000; Sun et al., 2002) and it is required for cell survival in different developmental contexts (Sun et al., 2002; Storm et al., 2003). To determine whether the observed failure of PThE and ETh development is caused by reduced cell proliferation, we analyzed cell proliferation in Fgf8 mutants at E11.5 and
E13.5 by detecting the expression of the M-phase cell cycle marker PH3. In WT embryos, we observed that the rate of cell proliferation in the ETh was higher at E11.5 than at later stages of development (E13.5) (Fig. 9A-F). Moreover, at E11.5 as well as at E13.5, WT embryos have a higher mitotic index in Th and ETh than in both mutants (Fig. 9M,N).

To confirm the role of Fgf8 in the control of proliferation in the diencephalic epithelium, we implanted cells that constitutively express Fgf8 into the epithalamic neuroepithelium of chick embryos at HH10. Controls consisted of injecting nontransfected cells, and the contralateral side was used as an internal experimental control. Subsequently, we explored the effect of Fgf 8 on proliferation in the epithalamus after $7 \mathrm{~d}$ of survival. Ectopic clusters of proliferating ventricular cells as well as a significant increase in the number of proliferating $\mathrm{PH} 3{ }^{+}$cells were observed in the ETh in which Fgf8-expressing cells had been injected (supplemental Fig. 1, available at www.jneurosci.org as supplemental material), whereas nontransfected cells did not produce any alteration on the experimental side (data not shown). These results indicate that Fgf8 expression in the ETh regulates the normal growth of the alar diencephalon, at least at the P2 level, by controlling neuroepithelial proliferation.

Apart from reduced cell proliferation, we found no significant differences in the number of caspase-3-labeled dying cells in the ETh of the Fgf8 mutant embryos, at neither the E11.5 nor the E13.5 developmental stages (Fig. 9G-N).

\section{Cell migration in the alar diencephalon}

Neuronal migration during neural development is currently being investigated using a variety of approaches (Lim and Golden, 2007). In our previous analysis of the diencephalic fate map in chick embryos (Garcia-Lopez et al., 2004), we found that a subpopulation of thalamic cells derived from the epithalamic grafts migrated into the thalamic mantle layer. By extension, the reduced thalamic area found in Fgf8 mutant embryos could possibly be a consequence of failure in this migration in mutant mice, since the ETh did not develop properly. To explore the existence of this migration in mice, we prepared organotypic cultures of wild-type prosencephalic neural tube and applied DiI to the ventricular side of the epithalamus (Fig. 10A). Twenty hours after placing the DiI crystal in the ETh, both the stria medullaris and the retroflexus tract were retrogradely and anterogradely labeled (Fig. 10B). Also, some DiI-labeled cells moved away from the ETh and proceeded ventrally following a tangential direction toward the thalamus (Fig. 10C, arrowheads). To exclude positive cellular artifacts attributable to retrograde labeling and confirm this dorsoventral migration by clonal and permanent cell labeling, we performed isotopic and isochronic transplants of ETh from E13.5 $\beta$-actin-GFP transgenic mice into an E13.5 WT host, using neuroepithelial explants. These analyses revealed that some 
epithalamic-derived cells (GFP cells) migrated toward the dorsal thalamus $(n=8$ of 12) (Fig. 10E,F).

Thus, these studies indicate that the reduction in size of the thalamus in Fgf 8 hypomorphs cannot be attributed uniquely to changes in cell specification and proliferation, through modifications in the expression of Wnt3a and Gbx2. Rather, this size reduction seems also to be attributable to a reduction in the number of thalamic cells which originate in the ETh and migrate to the thalamus. Nevertheless, additional analyses will be required to identify the target thalamic nuclei that will be populated by these cells, as well as the functional phenotype of these migrating cells.

\section{Discussion}

Our results showed that dosage in Fgf8 morphogenetic activity regulates diencephalic development. Decreased Fgf8 signaling results in cellular proliferation, migration, and regionalization defects.

\section{Fgf8 influences A/P patterning in the dorsal diencephalon}

The rostralization of Wnt1 expression in Fgf8 mutants could be interpreted as a caudalization of the P2 alar plate: Wnt 1 extends from P1 to cover the whole P2 roof plate, and Bmp4 expression was weaker than in WT and shifted rostrally. This is consistent with the caudalization of telencephalon after reduced Fgf signaling in zebrafish and mouse (Wilson and Houart, 2004; Storm et al., 2006). The consequences of these molecular alterations include the disappearance of the cpx in P2 and P3, as well as severe reduction of the pg (Fig. 11). These alterations could be attributable to the reduction of Bmp4 expression, since Bmp4 signaling could have a role in ETh development (Lim et al., 2005). However, Golden and coworkers (Golden, 1999; Lim and Golden, 2007) showed that, even though ectopic Bmp5,4 produced diencephalic modifications, blocking Bmp receptors did not significantly modify diencephalic anatomy. Therefore, it seems likely that the ETh phenotypes were not a consequence of $B m p 4$ reduction. Moreover, Bmp4 downregulation in Fgf8 hypomorphs disagrees with their antagonist relationship in the telencephalic roof plate (Storm et al., 2006; Hayhurst et al., 2008). Thus, the nature of $B m p 4$ regulation by $F g f 8$ expression exhibited regional specificity.

In contrast to findings in zebrafish (Carl et al., 2007; Bianco et al., 2008) in which the Wnt pathway regulates the bilaterality of the ETh, our results are not indicative of epithalamic asymmetry dependent on Wntl regulated by Fgf8.

Two recent papers dealing with Shh role in diencephalic development supported the independence of epithalamic development from Shh signal. Although Szabó et al. (2009) did not describe alterations in the ETh after the abolition of Shh signal in the diencephalon, Vue et al. (2009) reported alterations in the pretectum and habenular region (ETh) after an experimental reduction of Shh expression, but when ETh was illustrated it appeared structurally normal [Vue et al. (2009), their Figs. 5, 8].

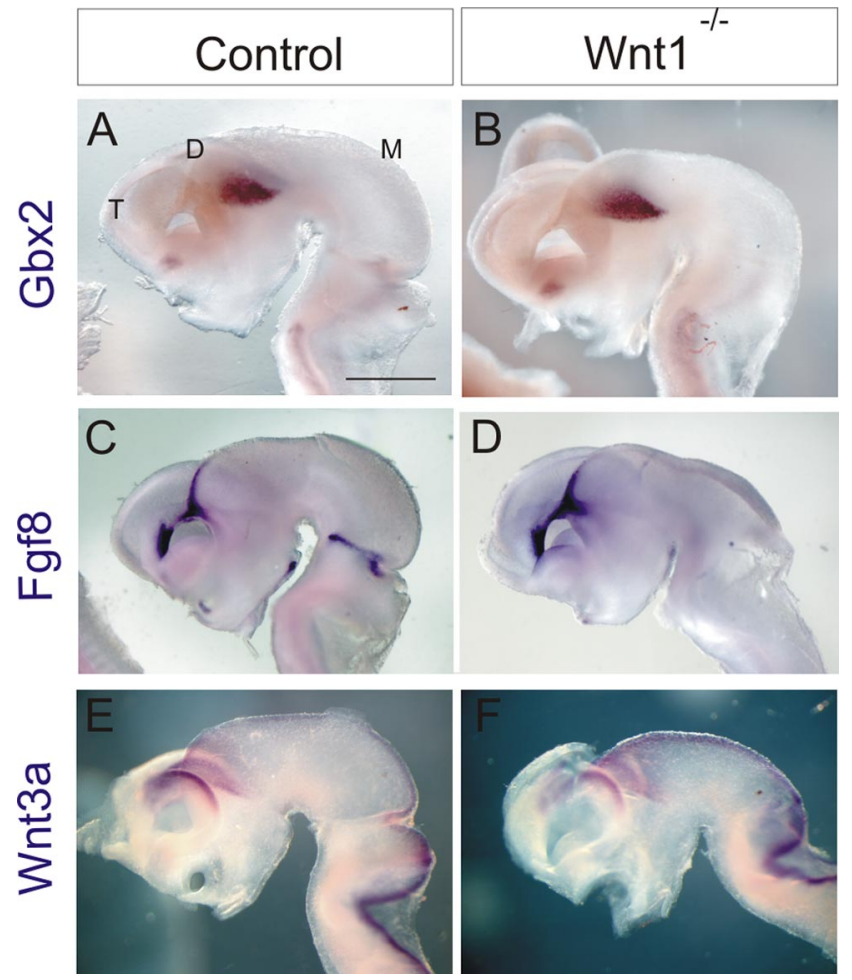

Figure 8. The expression of Gbx2, Fgf8, and Wnt3a are unaltered in $W_{n t 1}{ }^{-1-}$ embryos. Whole-mount in situ hybridization of E11.5 embryos showing Gbx2 $(\boldsymbol{A}, \boldsymbol{B})$, Fgf8 $(\boldsymbol{C}, \boldsymbol{D})$, and $W n t 3 a(\boldsymbol{E}, \boldsymbol{F})$ expression. $G b \times 2$, Fgf8, and Wnt3a expression domains appear normal in the diencephalon of Wnt1 mutant embryos. Abbreviations: D, Diencephalon; M, mesencephaIon; T, telencephalon. Scale bar: (in $\boldsymbol{A}) \boldsymbol{A}-\boldsymbol{F}, 1.3 \mathrm{~mm}$.

\section{Role of Fgf8 in the formation of the ZLI and prethalamus}

Fgf8 signal reduction gives rise to a progressive reduction in the expression of $S h h, N k x 2.1$, and $D l \times 5 / 2$ in the subpallial telencephalon (Storm et al., 2006). However, we did not find any alteration either in Shh expression in the ZLI (Fig. 2) or Dlx2 in the prethalamus (Fig. $7 D-F$ ). This discrepancy may be attributable to regional differences or variable phenotypic penetrance in the 

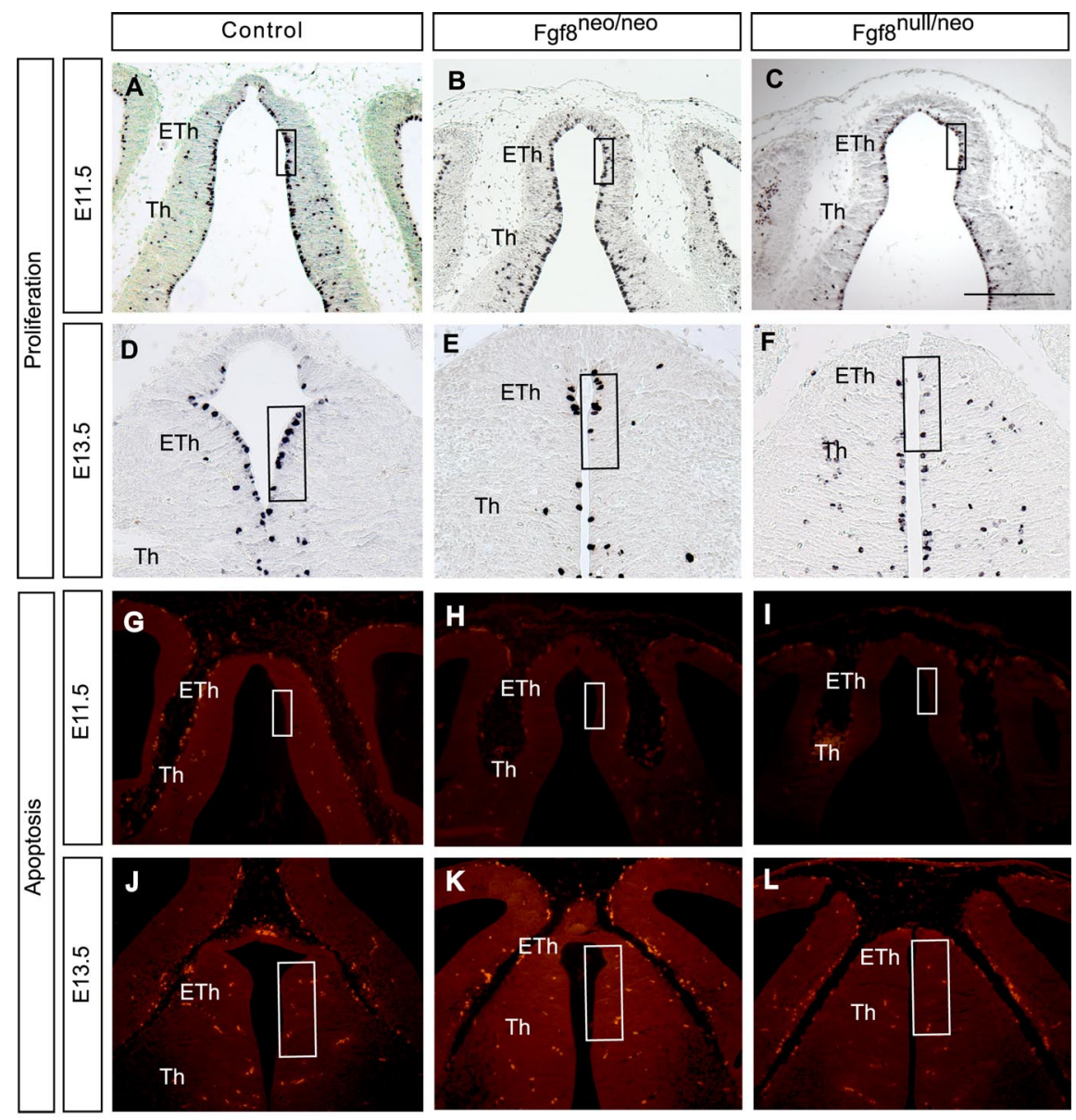

M

\begin{tabular}{cccc}
$\begin{array}{c}\text { Marker } \\
\text { assayed }\end{array}$ & $\begin{array}{c}\text { Number of } \\
\text { embryos }\end{array}$ & $\begin{array}{c}\text { Stage and } \\
\text { genotype }\end{array}$ & Values \\
\hline PH3 & 3 & E11.5 control & $12.8 \pm 1.57$ \\
PH3 & 2 & $E 11.5$ neo/neo & $8.25 \pm 2.06[0.0002]$ \\
PH3 & 2 & $E 11.5$ null/neo & $6.67 \pm 2.08[0.00002]$ \\
PH3 & 3 & $E 13.5$ control & $9.67 \pm 2.00$ \\
PH3 & 2 & $E 13.5$ neo/neo & $65 \pm 1.29[0.015]$ \\
PH3 & 2 & $E 13.5$ null/neo & $5.25 \pm 1.26[0.002]$ \\
Caspase-3 & 3 & $E 11.5$ control & $2.23 \pm 0.52$ \\
Caspase-3 & 1 & E11.5 neo/neo & $15 \pm 0.71[0.114]$ \\
Caspase-3 & 2 & $E 11.5$ null/neo & $1.5 \pm 0.50[0.115]$ \\
Caspase-3 & 3 & $E 13.5$ control & $3.8 \pm 0.84$ \\
Caspase-3 & 2 & E13.5 neo/neo & $4 \pm 1[0.770]$ \\
Caspase-3 & 2 & E13.5 null/neo & $35 \pm 1[0.638]$ \\
\hline
\end{tabular}

N

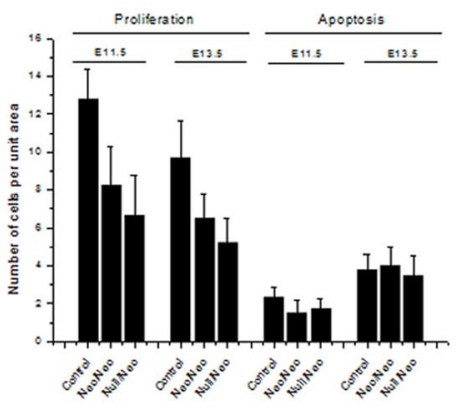

Figure 9. Proliferation, but not apoptosis, is altered in the epithalamus of Fgf8 $8^{\text {neo } / \text { neo }}$ and $F g f 8^{\text {null } / \text { neo }}$ mutant embryos. $\boldsymbol{A}-\boldsymbol{F}$, Immunohistochemistry using an anti-PH3 antibody on coronal sections of the diencephalon revealed severely reduced PH3 immunoreactivity in Fgf8 mutant embryos at E11.5 $(\boldsymbol{A}-\boldsymbol{C})$ and at E13.5 (D-F). Reduced PH3 immunolabeling correlates with reduced Fgf8 expression. $\mathbf{G}-\boldsymbol{L}$, Apoptotic cells were detected by caspase-3 immunofluorescence on coronal sections of the dien-

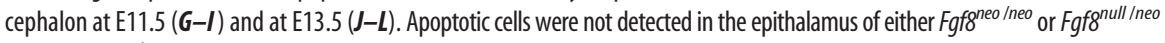
embryos. $\mathrm{PH}^{+}{ }^{+}$cells and apoptotic cells were counted in the epithalamus (boxes) located by Brn3a staining (data not shown) at E13.5 or by negative immunostaining for calbindin at E11.5. $M$, Table presenting the average number \pm SD per unit area of cellular nuclei labeled with PH3 and the average number of cells labeled with caspase-3. Results of $t$ test analyses are shown for each mutant compared with wild type. Values $<0.05$ are considered to be statistically significant. $\boldsymbol{N}$, Histograms presenting the average number ( $\pm S D$ ) of proliferating or apoptotic cells per unit area. Abbreviations: ETh, epithalamus; Th, thalamus. Scale bar: (in $C$ ) A-C, G-I, $270 \mu \mathrm{m} ; \boldsymbol{D}-\boldsymbol{F}, 210 \mu \mathrm{m} ; \boldsymbol{J}-\mathbf{L}, 230 \mu \mathrm{m}$.

Fgf $8^{\text {null } / \text { neo }}$ mutant, whereas Gbx2 expression in Fgfinull/neo embryos is consistently affected in the diencephalon, a reduction of Dlx2 expression in the telencephalon is not evident in all cases (data not shown). Kataoka and Shimogori (2008) reported alterations in the anterior thalamus (including part of the putative prethalamic nuclei), without epithalamic modification, after Fgf8 ectopic expression or Fgf signal repression by intrauterine electroporation. The absence of anterior thalamic and prethalamic alterations in the $F g f 8$ hypomorph embryos suggests that the remaining Fgf8 signal in the PThE was enough to maintain the development of this region. Alternatively, Fgf8 function in the mutant prethalamus could be compensated by Shh, or another Fgf gene, for instance, Fgf15, which is expressed in the diencephalon under Shh regulation (Gimeno et al., 2003; Gimeno and Martinez, 2007). In support of this functional compensation, combinatorial effects between $F g f 8$ and $F g f 3$ are known in zebrafish diencephalic development (Walshe and Mason, 2003).

\section{Fgf8 regulates the $\mathrm{D} / \mathrm{V}$ axis in}

\section{the diencephalon}

Dorsoventral regionalization is regulated during the neurulation by morphogenetic signals from the ventral and dorsal midlines. In the diencephalon, whereas the floor plate's ventralizing signal is Shh, the dorsalizing signals from the roof plate are Bmps and Wnts (Furuta et al., 1997; Braun et al., 2003; Zhou et al., 2004; Lim et al., 2005; Lavado et al., 2008). The mild consequences of Bmp4 elimination suggest a weak role in diencephalic development.

In relation to Wnt, extension of Wnt1 in the roof plate and reduction of Wnt $3 a$ expressions in the alar plate suggested a progressive caudalization of $\mathrm{P} 2$ between stages E10.5 to E12.5. Progressive caudalization of the anterior diencephalon at similar developmental stages has been reported in Six3 mutant mice (Lavado et al., 2008), suggesting that, even at intermediate stages of development, there is a dependence on specific molecular information to restrain tissue plasticity to the adequate developmental programs in the prosencephalon.

Interestingly, insertion of Fgf8 beads into the diencephalon of $F g f 8$ hypomorph embryos led to the activation of Wnt $3 a$ expression (Fig. 5). This implies that Fgf8 in the dorsal diencephalon is involved in establishing the thalamic expression of $W n t 3 a$. However, Fgf8 overexpression did not seem to affect Wnt3a (Kataoka and Shimogori, 2008). These paradoxical results could be attributable to the fact that our molecular rescue experiments were performed using mutant embryos, in which Fgf8 signaling is reduced since the beginning of gastrulation, whereas in the electroporated embryos, the primary effects of Fgf8 signaling could be sufficient to induce and stabilize Wnt3a expression. Additional Fgf8 signal did not alter 
Wnt3a expression pattern, probably because of saturation of the effect in restricted sensitive domains. In fact, Fgf8 beads implanted into control explants increased Wnt3a expression in its normal domains, regulated by the isthmic and diencephalic Fgf8 signal, but did not induce ectopic expression.

We observed a reduction in Gbx2 expression in the thalamic neuroepithelium of mutants (Fig. 7). Fgf8 signaling induce and maintain $G b \times 2$ expression in the midbrain and diencephalon of chick embryos (Garda et al., 2001; Sato et al., 2001), whereas in mouse, both Fgf8 and Wnt3a regulate $G b \times 2$ expression (Liu and Joyner, 2001). Interestingly, in $W n t 1^{-1-}$ embryos, neither Fgf8, Wnt3a, nor Gbx2 expression in the diencephalon was affected, despite the potential role of Wnt signaling in thalamic development (Braun et al., 2003; Zhou et al., 2004). Alternatively Wnt3a expression could maintain $G b \times 2$ in the $W n t 1^{-1-}$ thalamus. Together, these data indicate that the epithalamic and thalamic neuroepithelium is regionalized by, and competent to respond to, Fgf8 signaling independently of $W n t 1$ expression.

Similar defects in Fgf8 hypomorphs could be predicted after Fgf receptor (Fgfr) functional disequilibrium. Fgfr 3 is the most sensitive receptor for the Fgf8 signal and it is expressed in the diencephalic alar plate (Blak et al., 2005; Mason, 2007). Whereas Fgfr3 loss of function produces growth alterations and deafness in mouse (Colvin et al., 1996), its constitutive activation generates thanatophoric dysplasia (TD) in mouse (Lin et al., 2003) and humans (Hevner, 2005). Habenular and pineal hypogenesis is apparent in TD type II, in mouse (Lin et al., 2003) and humans [Hevner (2005), their Figs. $3 A, C$, $4 A, D]$. This could be attributable to increased sprouty 2 (Spry2) activity (Guo et al., 2008) that negatively regulates Fgf8 (Basson et al., 2008). Conversely, Spry2 could not have a repressive activity on the Fgf8 signal in the telencephalon, in which constitutive activation of Fgfr3 produces overgrowth (Lin et al., 2003; Hevner, 2005) in keeping with the regional specificity of Fgf8 signal regulation.

Fgf8 regulates cellular proliferation and migration in the dorsal diencephalon Fgf8 has been shown to stimulate cell proliferation in the midbrain/hindbrain region (Lee et al., 1997; Xu et al., 2000; Storm et al., 2006) and in the forebrain (Storm et al., 2006). In our study, the epithalamus of $\mathrm{Fgf8}$ mutants exhibited reduced proliferation in the absence of cell
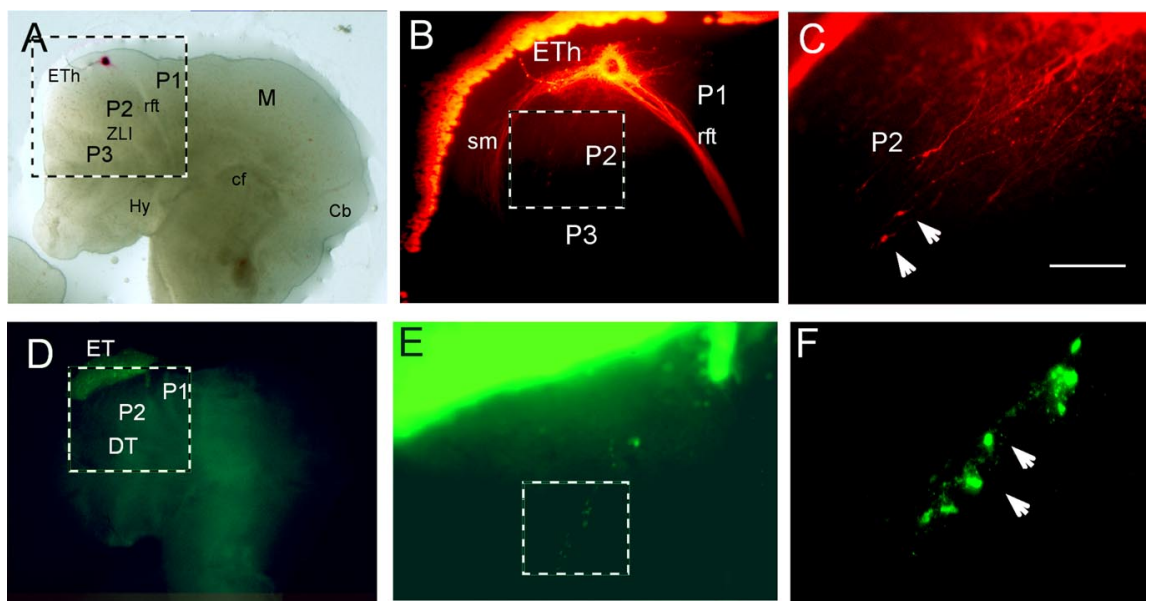

Figure 10. Some thalamic neurons originate from the epithalamus. $\boldsymbol{A}-\boldsymbol{C}$, Implantation of Dil crystals. $\boldsymbol{A}$, The Dil crysta was implanted in the epithalamus of E13.5 embryos. $\boldsymbol{B}, \boldsymbol{C}$, After $20 \mathrm{~h}$, Dil-labeled cells were observed in the dorsal thalamus. $\boldsymbol{D}-\boldsymbol{F}$, Transplantation of epithalamus from GFP mutant mice $\left(E T h^{\mathrm{GFP}}\right)$ into the epithalamus of ICR mice (Eth $\left.{ }^{\mathrm{ICR}}\right)$. D, Picture from the transplanted region. Several epithalamic cells move away from the transplanted region toward the thalamus $(\boldsymbol{E}, \boldsymbol{F})$ after $24 \mathrm{~h}$ of incubation. $\boldsymbol{B}, \boldsymbol{C}, \boldsymbol{E}, \boldsymbol{F}$, Higher magnification of the squares represented in $\boldsymbol{A}, \boldsymbol{B}, \boldsymbol{D}$, and $\boldsymbol{E}$, respectively. The arrowheads in $\boldsymbol{C}$ and $\boldsymbol{F}$ indicate cells migrating ventrally from the epithalamus toward the thalamus. Abbreviations: Cb, Cerebellum; $\mathrm{Cf}$, cephalic flexure; DT, dorsal thalamus; ET, epithalamus; Hy, hypothalamus; M, mesencephalon; P1, prosomere 1; P2, prosomere 2, P3, prosomere 3; rft, retroflexus tract; sm, stria medullaris. Scale bar: (in $\boldsymbol{C}) \boldsymbol{A}, \boldsymbol{D}, \sim 800 \mu \mathrm{m} ; \boldsymbol{B}, \boldsymbol{E}, \sim 600 \mu \mathrm{m} ; \boldsymbol{C}, \boldsymbol{F}, \sim 200 \mu \mathrm{m}$.
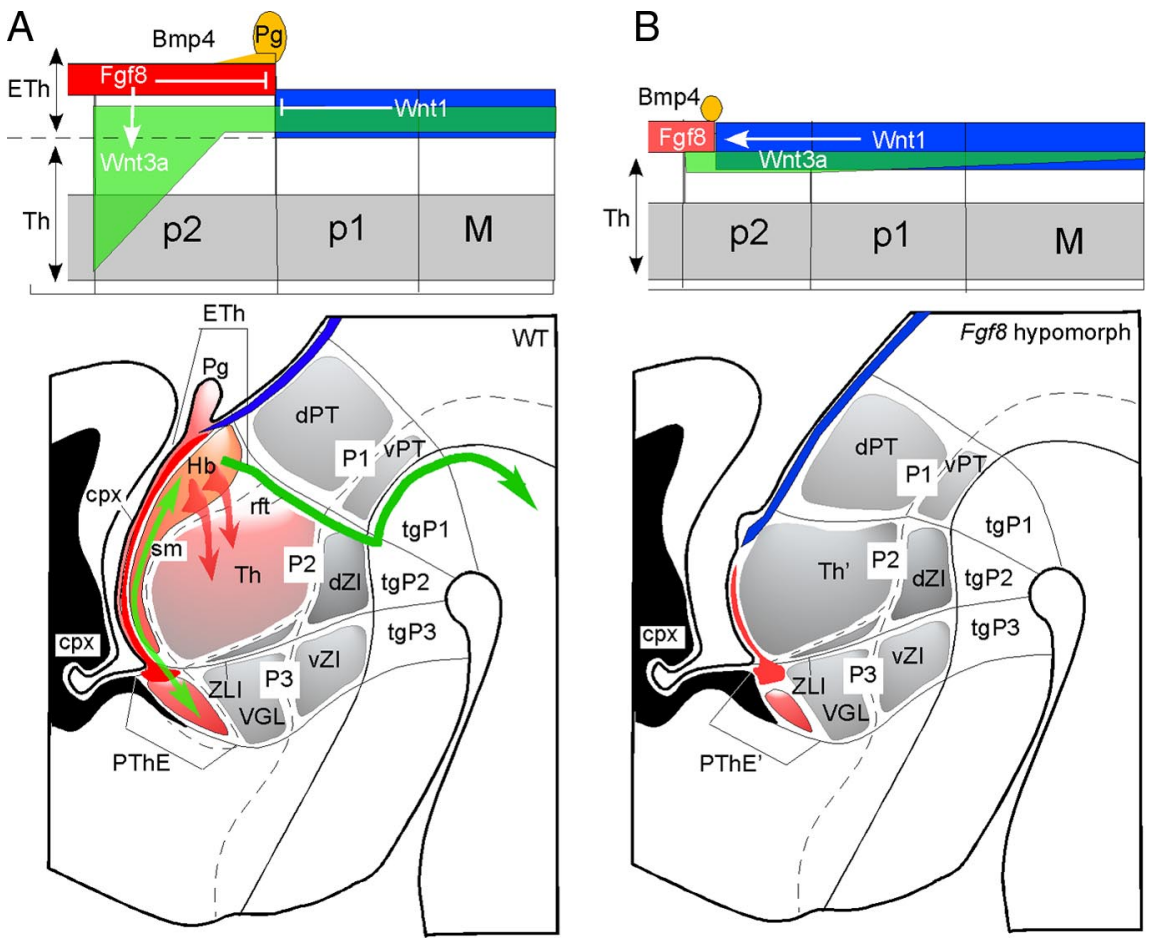

Figure 11. Schematic representation illustrating diencephalic regionalization and its relation to morphogens expressed in the diencephalic neuroepithelium. The morphogenetic activity of Bmp, Wnt, and Fgf involves a gradient effect on the diencephalic alar plate, which influences ventrodorsal and anteroposterior regionalization. The Fgf 8 morphogenetic gradient from the roof plate, represented by the graded light red color, controls the expression of diencephalic selector genes and is necessary for the correct specification of the diencephalic regions in vertebrates. $A$, Diencephalic nuclear organization in wild-type embryos. Nuclei that are capable of responding to Fgf8 are represented in red shading. $\boldsymbol{B}$, Diencephalic nuclear organization in Fgf8 hypomorphs and its relation to other genes. Abbreviations: ETh, epithalamus; Th, thalamus; $\mathrm{Pg}$, pineal gland; Hb, habenula; cpx, choroid plexus; sm, stria medullaris; dPT, dorsal pretectum; rft, retroflex tract; ZLI, zona limitans intrathalamica; VGL, ventrolateral geniculate nucleus; P1, prosomere 1; P2, prosomere 2; P3, prosomere 3; vPT, ventral pretectum; dZI, dorsal zona incerta; vZl, ventral zona incerta; $\operatorname{tg} P 1, \operatorname{tg} P 2, \operatorname{tg} P 3$, tegmental areas of $P 1, P 2$, and P3; M, mesencephalon; PThE, prethalamic eminence. 
death increasing. Consistently, injection of Fgf8-expressing cells into the epithalamus of chick embryos activated proliferation (supplemental Fig. 1, available at www.jneurosci.org as supplemental material). Thus, Fgf8 signaling could serve as a mitogenic signal that regulates dorsal diencephalic growth by controlling precursor proliferation. Curiously, reduced Fgf8 signaling in the diencephalon did not lead to an increase in cell death, in contrast to that which occurs in the midbrain/hindbrain region (Chi et al., 2003).

Furthermore, some cells in the dorsal thalamus were found to originate from the epithalamus in mouse (Figs. 10,11) and chick embryos (Garcia-Lopez et al., 2004). Smith et al. (2006) suggested a role for Fgf8 in cell migration since exogenous Fgf8 induced the migration of cells from the ventricular zone to the cortical plate.

\section{Evolutionary hypothesis}

These experiments suggest that the expression of Fgf8 in the prosencephalic roof plate leads to the development of a dorsal column in vertebrates, which extends from the anterior telencephalon to the caudalmost P2 domain in the diencephalon. This column develops into the telencephalic pallium and the diencephalic PThE and ETh, which do not exist in primitive chordate species, such as the urochordata. Ascidians present a segment of Fgf8 expression analogous to the vertebrate midbrain/hindbrain. Conversely, they do not express Fgf8 in more rostral areas, especially in the corresponding prosencephalon; neither do they possess a pineal gland or habenular region (Ikuta and Saiga, 2007). Therefore, the appearance of this dorsal paramedian region in vertebrates could be attributable to a phylogenetic addition (Striedter, 2005) by the de novo expression of Fgf8 in the prosencephalic roof plate. Functional maturation of ETh would then be an anatomical substrate to support the development of adaptive control of motor function in the vertebrate brain.

\section{References}

Alexandre P, Bachy I, Marcou M, Wassef M (2006) Positive and negative regulations by FGF8 contribute to midbrain roof plate developmental plasticity. Development 133:2905-2913.

Andres KH, Von Düring M, Veh RW (1999) Subnuclear organization of the rat habenular complexes. J Comp Neurol 407:130-150.

Basson MA, Echevarría D, Ahn CP, Sudarov A, Joyner AL, Mason IJ, Martinez S, Martin GR (2008) Specific regions within the embryonic midbrain and cerebellum require different levels of FGF signaling during development. Development 135:889-898.

Bianco IH, Carl M, Russell C, Clarke JD, Wilson SW (2008) Brain asymmetry is encoded at the level of axon terminal morphology. Neural Dev 31:3-9.

Blak AA, Naserke T, Weisenhorn DM, Prakash N, Partanen J, Wurst W (2005) Expression of Fgf receptors 1, 2, and 3 in the developing mid- and hindbrain of the mouse. Dev Dyn 233:1023-1030.

Braun MM, Etheridge A, Bernard A, Robertson CP, Roelink H (2003) Wnt signaling is required at distinct stages of development for the induction of the posterior forebrain. Development 130:5579-5587.

Bulfone A, Puelles L, Porteus MH, Frohman MA, Martin GR, Rubenstein JLR (1993) Spatially restricted expression of Dlx-1, Dlx-2 (Tes-1), Gbx-2, and Wnt-3 in the embryonic day 12.5 mouse forebrain defines potential transverse and longitudinal segmental boundaries. J Neurosci 17:3155-3172.

Carl M, Bianco IH, Bajoghli B, Aghaallaei N, Czerny T, Wilson SW (2007) Wnt/Axin 1/beta-catenin signaling regulates asymmetric nodal activation, elaboration, and concordance of CNS asymmetries. Neuron 55:393-405.

Chi CL, Martinez S, Wurst W, Martin GR (2003) The isthmic organizer signal FGF8 is required for cell survival in the prospective midbrain and cerebellum. Development 130:2633-2644.

Colvin JS, Bohne BA, Harding GW, McEwen DG, Ornitz DM (1996) Skeletal overgrowth and deafness in mice lacking fibroblast growth factor receptor 3. Nat Genet 12:390-397.
Crossley PH, Martin GR (1995) The mouse Fgf8 gene encodes a family of polypeptides and is expressed in regions that direct outgrowth and patterning in the developing embryo. Development 121:439-451.

Crossley PH, Martinez S, Martin GR (1996) Midbrain development induced by FGF8 in the chick embryo. Nature 380:66-68.

Crossley PH, Martinez S, Ohkubo Y, Rubenstein JLR (2001) Coordinate expression of Fgf8, Otx2, Bmp4 and Shh in the rostral prosencephalon during development of the telencephalic and optic vesicles. Neuroscience 108:183-206.

Echevarría D, Vieira C, Martinez S (2001) Mammalian neural tube grafting experiments: an in vitro system for mouse experimental embryology. Int J Dev Biol 45:895-902.

Echevarría D, Vieira C, Gimeno L, Martinez S (2003) Neuroepithelial secondary organizers and cell fate specification in the developing brain. Brain Res Rev 43:179-191.

Echevarría D, Martinez S, Marques S, Lucas-Teixeira V, Belo JA (2005) Mkp3 is a negative feedback modulator of Fgf8 signaling in the mammalian isthmic organizer. Dev Biol 277:114-128.

Furuta Y, Piston DW, Hogan BLM (1997) Bone morphogenetic proteins (BMPs) as regulators of dorsal forebrain development. Development 124:2203-2212.

Garcia-Lopez R, Vieira C, Echevarría D, Martinez S (2004) Fate map of the diencephalon and the zona limitans at the 10-somites stage in chick embryos. Dev Biol 268:514-530.

Garda AL, Echevarría D, Martínez S (2001) Neuroepithelial co-expression of $G b \times 2$ and $O t \times 2$ precedes $F g f 8$ expression in the isthmic organizer. Mech Dev 101:111-118.

Garel S, Huffman KJ, Rubenstein JLR (2003) Molecular regionalization of the neocortex is disrupted in Fgf8 hypomorphic mutants. Development 130:1903-1914.

Gimeno L, Martinez S (2007) Expression of chick Fgf19 and mouse Fgf15 orthologs is regulated in the developing brain by Fgf8 and Shh. Dev Dyn 236:2285-2297.

Gimeno L, Brûlet P, Martínez S (2003) Study of Fgf15 gene expression in developing mouse brain. Gene Expr Patterns 3:473-481.

Golden JA (1999) Towards a greater understanding of the pathogenesis of holoprosencephaly. Brain Dev 21:513-521.

Guo C, Degnin CR, Laederich MB, Lunstrum GP, Holden P, Bihlmaier J, Krakow D, Cho YJ, Horton WA (2008) Sprouty 2 disturbs FGFR3 degradation in thanatophoric dysplasia type II: a severe form of human achondroplasia. Cell Signal 8:1471-1477.

Hamburger V, Hamilton HL (1951) A series of normal stages in the development of the chick embryo. J Morphol 88:49-92.

Hayhurst M, Gore BB, Tessier-Lavigne M, McConnell SK (2008) Ongoing sonic hedgehog signaling is required for dorsal midline formation in the developing forebrain. Dev Neurobiol 68:83-100.

Hébert JM, Mishina Y, McConnell SK (2002) BMP signaling is required locally to pattern the dorsal telencephalic midline. Neuron 35:1029-1041.

Hevner RF (2005) The cerebral cortex malformation in thanatophoric dysplasia: neuropathology and pathogenesis. Acta Neuropathol 110:208-221.

Hikosaka O, Sesack SR, Lecourtier L, Shepard PD (2008) Habenula: crossroad between the basal ganglia and the limbic system. J Neurosci 28:11825-11829.

Ikuta T, Saiga H (2007) Dynamic change in the expression of developmental genes in the ascidian central nervous system: revisit to the tripartite model and the origin of the midbrain-hindbrain boundary region. Dev Biol 312:631-643.

Kataoka A, Shimogori T (2008) Fgf8 controls regional identity in the developing thalamus. Development 135:2873-2881.

Kiecker C, Lumsden A (2004) Hedgehog signaling from the ZLI regulates diencephalic regional identity. Nat Neurosci 7:1242-1249.

Larsen CW, Zeltser LM, Lumsden A (2001) Boundary formation and compartition in the avian diencephalon. J Neurosci 21:4699-4711.

Lavado A, Lagutin OV, Oliver G (2008) Six3 inactivation causes progressive caudalization and aberrant patterning of the mammalian diencephalon. Development 135:441-450.

Lee SM, Danielian PS, Fritzsch B, McMahon AP (1997) Evidence that FGF8 signalling from the midbrain-hindbrain junction regulates growth and polarity in the developing midbrain. Development 124:959-969.

Lim Y, Golden JA (2007) Patterning the developing diencephalon. Brain Res Rev 53:17-26. 
Lim Y, Cho G, Minarcik J, Golden J (2005) Altered BMP signaling disrupts chick diencephalic development. Mech Dev 122:603-620.

Lin T, Sandusky SB, Xue H, Fishbein KW, Spencer RG, Rao MS, Francomano CA (2003) A central nervous system specific mouse model for thanatophoric dysplasia type II. Hum Mol Genet 12:2863-2871.

Liu A, Joyner AL (2001) EN and GBX2 play essential roles downstream of FGF8 in patterning the mouse mid/hindbrain region. Development 128:181-191.

Louvi A, Yoshida M, Grove EA (2007) The derivatives of the Wnt3a lineage in the central nervous system. J Comp Neurol 504:550-569.

Martinez S, Crossley PH, Cobos I, Rubenstein JL, Martin GR (1999) FGF8 induces formation of an ectopic isthmic organizer and isthmocerebellar development via a repressive effect on Otx2 expression. Development 126:1189-1200.

Mason I (2007) Initiation to end point: the multiple roles of fibroblast growth factors in neural development. Nat Rev Neurosci 8:583-596.

Matsumoto M, Hikosaka O (2007) Lateral habenula as a source of negative reward signals in dopamine neurons. Nature 447:1111-1115.

McMahon AP, Joyner AL, Bradley A, McMahon JA (1992) The midbrainhindbrain phenotype of Wnt1-/Wnt1 - mice results from stepwise deletion of engrailed-expressing cells by 9.5 days postcoitum. Cell 69:581-595.

Meyers EN, Lewandoski M, Martin GR (1998) An Fgf8 mutant allelic series generated by Cre- and Flp-mediated recombination. Nat Genet 18:136141.

Nakamura H, Sato T, Suzuki-Hirano A (2008) Isthmus organizer for mesencephalon and metencephalon. Dev Growth Differ 50:113-118.

Okabe M, Ikawa M, Kominami K, Nakanishi T, Nishimune Y (1997) "Green mice" as a source of ubiquitous green cells. FEBS Lett 407:313-319.

Puelles E, Acampora D, Lacroix E, Signore M, Annino A, Tuorto F, Filosa S, Corte G, Wurst W, Ang S-L, Simeone A (2003) Otx dose-dependent integrated control of antero-posterior and dorso-ventral patterning of midbrain. Nat Neurosci 6:453-460.

Puelles L, Rubenstein JL (2003) Forebrain gene expression domains and the evolving prosomeric model. Trends Neurosci 26:469-476.

Rubenstein JL, Martinez S, Shimamura K, Puelles L (1994) The embryonic vertebrate forebrain: the prosomeric model. Science 266:578-580.

Sato T, Araki I, Nakamura H (2001) Inductive signal and tissue responsiveness defining the tectum and the cerebellum. Development 128:24612469.

Scholpp S, Wolf O, Brand M, Lumsden A (2006) Hedgehog signalling from the zona limitans intrathalamica orchestrates patterning of the zebrafish diencephalon. Development 133:855-864.

Shimamura K, Hirano S, McMahon AP, Takeichi M (1994) Wnt-1- dependent regulation of local E-cadherin and alpha N-catenin expression in the embryonic mouse brain. Development 120:2225-2234.

Smith KM, Ohkubo Y, Maragnoli ME, Rasin MR, Schwartz M, Sestan N, Vaccarino FM (2006) Midline radial glia translocation and corpus callosum formation require FGF signaling. Nat Neurosci 9:787-797.

Storm EE, Rubenstein JL, Martin GR (2003) Dosage of Fgf8 determines whether cell survival is positively of negatively regulated in the developing forebrain. Proc Natl Acad Sci U S A 100:1757-1762.

Storm EE, Garel S, Borello U, Hebert JM, Martinez S, McConnell SK, Martin GR, Rubenstein JL (2006) Dose-dependent functions of $F g f 8$ in regulating telencephalic patterning centers. Development 133:1831-1844.

Striedter GF (2005) Principles of brain evolution, pp 177-215. Sunderland, MA: Sinauer Associates.

Sun X, Mariani FV, Martin GR (2002) Functions of FGF signalling from the apical ectodermal ridge in limb development. Nature 418:501-508.

Szabó NE, Zhao T, Zhou X, Alvarez-Bolado G (2009) The role of sonic hedgehog of neural origin in thalamic differentiation in the mouse. J Neurosci 29:2453-2466.

Vieira C, Martinez S (2005) Experimental study of MAP kinase phosphatase-3 $(M k p 3)$ expression in the chick neural tube in relation to Fgf8 activity. Brain Res Rev 49:158-166.

Vieira C, Martinez S (2006) Sonic Hedgehog from the basal plate and the zona limitans intrathalamica exhibits differential activity on diencephalic molecular regionalization and nuclear structure. Neuroscience 143:129-140.

Vieira C, Garda AL, Shimamura K, Martinez S (2005) Thalamic development induced by Shh in the chick embryo. Dev Biol 284:351-363.

Vue TY, Bluste K, Alishahi A, Yang LL, Koano-Nakagawa N, Novitch B, Nakagawa Y (2009) Sonic hedgehog signaling controls thalamic progenitor identity and nuclei specification in mice. J Neurosci 29:44844497.

Walshe J, Mason I (2003) Unique and combinatorial functions of Fgf3 and Fgf8 during zebrafish forebrain development. Development 130:43374349.

Wilson SW, Houart C (2004) Early steps in the development of the forebrain. Dev Cell 6:167-181.

Xu J, Liu Z, Ornitz DM (2000) Temporal and spatial gradients of Fgf8 and Fof17 regulate proliferation and differentiation of midline cerebellar structures. Development 127:1833-1843.

Yamaguchi TP (2001) Heads or tails: Wnts and anterior-posterior patterning. Curr Biol 11:713-724.

Zeltser LM (2005) Shh-dependent formation of the ZLI is opposed by signals from the dorsal diencephalon. Development 132:2023-2033.

Zhou C, Pinson KI, Pleasure SJ (2004) Severe defects in dorsal thalamic development in low-density lipoprotein receptor-related protein-6 mutants. J Neurosci 24:7632-7639. 